\title{
Tropical cyclone contribution to extreme rainfall over southwest Pacific Island nations
}

\author{
Anil Deo ${ }^{1} \cdot$ Savin S. Chand ${ }^{1} \cdot$ Hamish Ramsay ${ }^{2} \cdot$ Neil J. Holbrook $^{3}$. Simon McGree ${ }^{4}$ Andrew Magee ${ }^{5} \cdot$ Samuel Bell $^{1}$. \\ Mulipola Titimaea $^{6} \cdot$ Alick Haruhiru $^{7} \cdot$ Philip Malsale $^{8} \cdot$ Silipa Mulitalo $^{6} \cdot$ Arieta Daphne $^{9} \cdot$ Bipen Prakash $^{9}$. \\ Vaiola Vainikolo ${ }^{10}$. Shirley Koshiba ${ }^{11}$
}

Received: 23 June 2020 / Accepted: 28 January 2021 / Published online: 18 March 2021

(c) The Author(s) 2021

\begin{abstract}
Southwest Pacific nations are among some of the worst impacted and most vulnerable globally in terms of tropical cyclone (TC)-induced flooding and accompanying risks. This study objectively quantifies the fractional contribution of TCs to extreme rainfall (hereafter, TC contributions) in the context of climate variability and change. We show that TC contributions to extreme rainfall are substantially enhanced during active phases of the Madden-Julian Oscillation and by El Niño conditions (particularly over the eastern southwest Pacific region); this enhancement is primarily attributed to increased TC activity during these event periods. There are also indications of increasing intensities of TC-induced extreme rainfall events over the past few decades. A key part of this work involves development of sophisticated Bayesian regression models for individual island nations in order to better understand the synergistic relationships between TC-induced extreme rainfall and combinations of various climatic drivers that modulate the relationship. Such models are found to be very useful for not only assessing probabilities of TC- and non-TC induced extreme rainfall events but also evaluating probabilities of extreme rainfall for cases with different underlying climatic conditions. For example, TC-induced extreme rainfall probability over Samoa can vary from $\sim 95$ to 75\% during a La Niña period, if it coincides with an active or inactive phase of the MJO, and can be reduced to 30\% during a combination of El Niño period and inactive phase of the MJO. Several other such cases have been assessed for different island nations, providing information that have potentially important implications for planning and preparing for TC risks in vulnerable Pacific Island nations.
\end{abstract}

Keywords Tropical cyclones · Extreme rainfall · Madden Julian oscillation · El Nino Southern oscillation · Southwest Pacific island nations

Anil Deo

a.deo@federation.edu.au

1 School of Engineering, Information Technology and Physical Sciences, Federation University Australia, Mt Helen Campus, Mt Helen, VIC, Australia

2 CSIRO, Oceans and Atmosphere, Aspendale, VIC, Australia

3 Institute for Marine and Antarctic Studies and ARC Centre of Excellence for Climate Extremes, University of Tasmania, Hobart, Australia

4 Australian Bureau of Meteorology, Melbourne, Australia

5 Centre for Water, Climate and Land, The University of Newcastle, Callaghan, NSW, Australia
6 Samoa Meteorological Services, Apia, Samoa

7 Solomon Islands Meteorological Service, Honiara, Solomon Islands

8 Secretariat of the Pacific Regional Environment Programme, Apia, Samoa

$9 \quad$ Fiji Meteorological Services, Nadi, Fiji

10 Tonga Meteorological Services, Nuku'alofa, Tonga

11 Palau International Coral Reef Centre, Koror, Palau 


\section{Introduction}

Tropical cyclones (TCs) play a prominent role in driving or contributing to extreme rainfall in different parts of the world (e.g., Lau et al. 2008; Knight and Davis 2009; Wang et al. 2009; Jiang and Zipser 2010; Chen et al. 2013; Villarini and Denniston 2015; Khouakhi et al. 2017), and can cause devastating impacts through extensive flooding (e.g., Woodruff et al. 2013; Callaghan and Power 2014; Villarini et al. 2014; Power and Callaghan 2016; Aryal et al. 2019; Paerl et al. 2019) and landslides (e.g., Antinao and Farfán 2013; Cogan et al. 2018). The extent of TC contributions to extreme rainfall-and hence, the nature of impacts associated with TC-driven rainfall — can vary between regions depending on their geographical locations and exposure to TC incidences (e.g. Knight and Davis 2009; Jiang and Zipser 2010; Villarini and Denniston 2015; Zhang et al. 2018), as well as their community vulnerability and adaptive capacity to TC risks (e.g., Peduzzi et al. 2012).

At a global scale, $10 \%$ of Florida's annual rainfall is contributed by TCs (Knight and Davis 2007) while annual contributions of $20-40 \%$ has been reported over Taiwan and South-eastern China (Ren et al. 2006). In the Philippines, TC contribution to annual rainfall ranges from $6 \%$ in the southern regions to $54 \%$ over the northern regions (Bagtasa 2017). Over Australia, during the peak TC season (January-March), TCs contribute greater than $30 \%$ to the rainfall total of coastal regions west of $120^{\circ} \mathrm{E}$, while during December, TCs contribute approximately $60-70 \%$ to the total rainfall west of $115^{\circ} \mathrm{E}$, making it one of the regions of the globe where this fraction is greatest (Dare et al 2012); some stations west of $115^{\circ} \mathrm{E}$ can have more than $70 \%$ of rainfall from TCs in the October through December period (Ng et al. 2015).

The highest fractional contributions of TC-induced extreme rainfall occur largely in the exposed coastal areas of eastern Asia (such as Japan and the Philippines), followed by northwest Australia and the U.S. East Coast, with fractional contributions generally decreasing farther inland from the coast (Khouakhi et al. 2017). Over the south-eastern U.S. coast, major TCs (category 3-5) are found to produce the most extreme rainfall days, but tropical depression/storm days contribute most significantly to cumulative seasonal rainfall (8-17\%, basin-dependent) due to frequency of occurrence (Shepherd et al 2007). Extreme precipitation from TCs over the same region has been increasing over the past few decades and a significant increase in the contribution of TC precipitation to overall extreme precipitation by approximately $5-10 \%$ per decade has also been reported (Knight and Davis 2007). Over Australia, the study by Villarini and Denniston (2015) shows that more than half of the highest annual rainfall events are associated with TCs over the coastal regions and in particular over Western Australia. This study further shows that TC fractional contribution to extreme rainfall increases with largest rainfall events, with approximately $66-100 \%$ of annual maximum in excess of $100 \mathrm{~mm}$ over Western Australia associated with TCs at over one third of the locations. Moreover, a larger probability of having an annual rainfall maximum related to TCs occurs during La Niña years which is consistent with the findings of Khouakhi et al. (2017).

The high volcanic Small Island nations in the southwest Pacific (SWP, see Fig. 1a, b) basin are also among some of the most impacted areas globally in terms of TC-induced flooding and accompanying risks (Nurse et al. 2014). However, current understanding of TC-induced extreme rainfall for these Island nations is mainly qualitative and, as far as we are aware, no literature as yet exists to objectively quantify TC contributions to extreme rainfall in the context of climate variability and change. Here, we attempt to reduce these knowledge gaps by investigating the nature and patterns of TC-induced extreme rainfall events for SWP Island nations and to examine case studies of events that have caused unprecedented impacts on local communities in order to better understand their occurrences.

A characteristic feature in the South Pacific Ocean is the South Pacific Convergence Zone (SPCZ; Vincent 1994). The SPCZ is a region of low-level moisture convergence that often provides much of the rainfall to SWP Island nations (e.g., Griffiths et al. 2003; McGree et al. 2019). TCs (and weak depressions) are frequently spawned within the SPCZ and can play a significant role in redirecting and transporting large amounts of moisture from the moisture-laden SPCZ to the islands that lie along TC trajectories. This mechanism of moisture transport for the SWP (i.e., from an already established background moisture convection) is similar to what is documented, for example, for the East Asia monsoon region where TCs can provide intense rainfall over the south China coast and Taiwan, or to higher latitude regions of the Korean Peninsula and Japan that often lie along TC trajectories (Guo et al. 2017). Both the SPCZ and TCs in the SWP region undergo substantial variability at multiple timescales, and so it is anticipated that TC-induced extreme rainfall will accordingly show similar patterns of variability. For the purpose of this study, we focus on intraseasonal to annual modes of climate variability (and not longer-term trends) due to the availability of limited time series of reliable TC data records for the SWP.

The Madden-Julian Oscillation (MJO; Madden and Julian 1971, 1994) is an eastward-propagating equatorial disturbance with a period of about 30-90 days (e.g., Zhang $2005)$, and is a primary driver of variability in position of the SPCZ (Matthews et al. 1996; Matthews 2012; Haffke and Magnusdottir 2013) and SWP TC genesis and intensity 
Fig. 1 a Location of the SWP Island nations relative to the globe, $\mathbf{b}$ average occurrence of TCs per decade over stations in the SWP Island nations for the period 1970-2018 (the total number of TCs that appeared within $500 \mathrm{~km}$ from each station during the study period are used here) and $\mathbf{c}$ the overall mean monthly rainfall rate for November to April for the period 1970-2018 (a) Location of SWP Island nations relative to the Globe

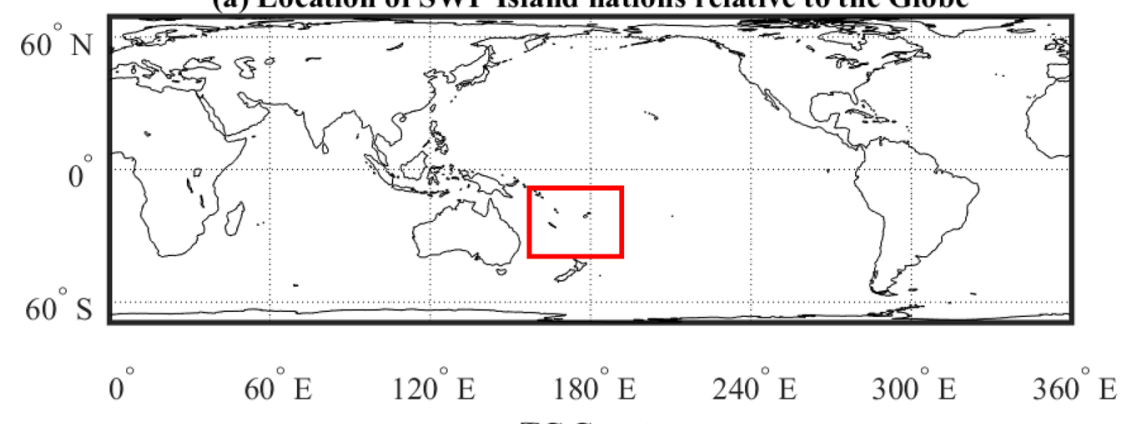

(b) TC Counts
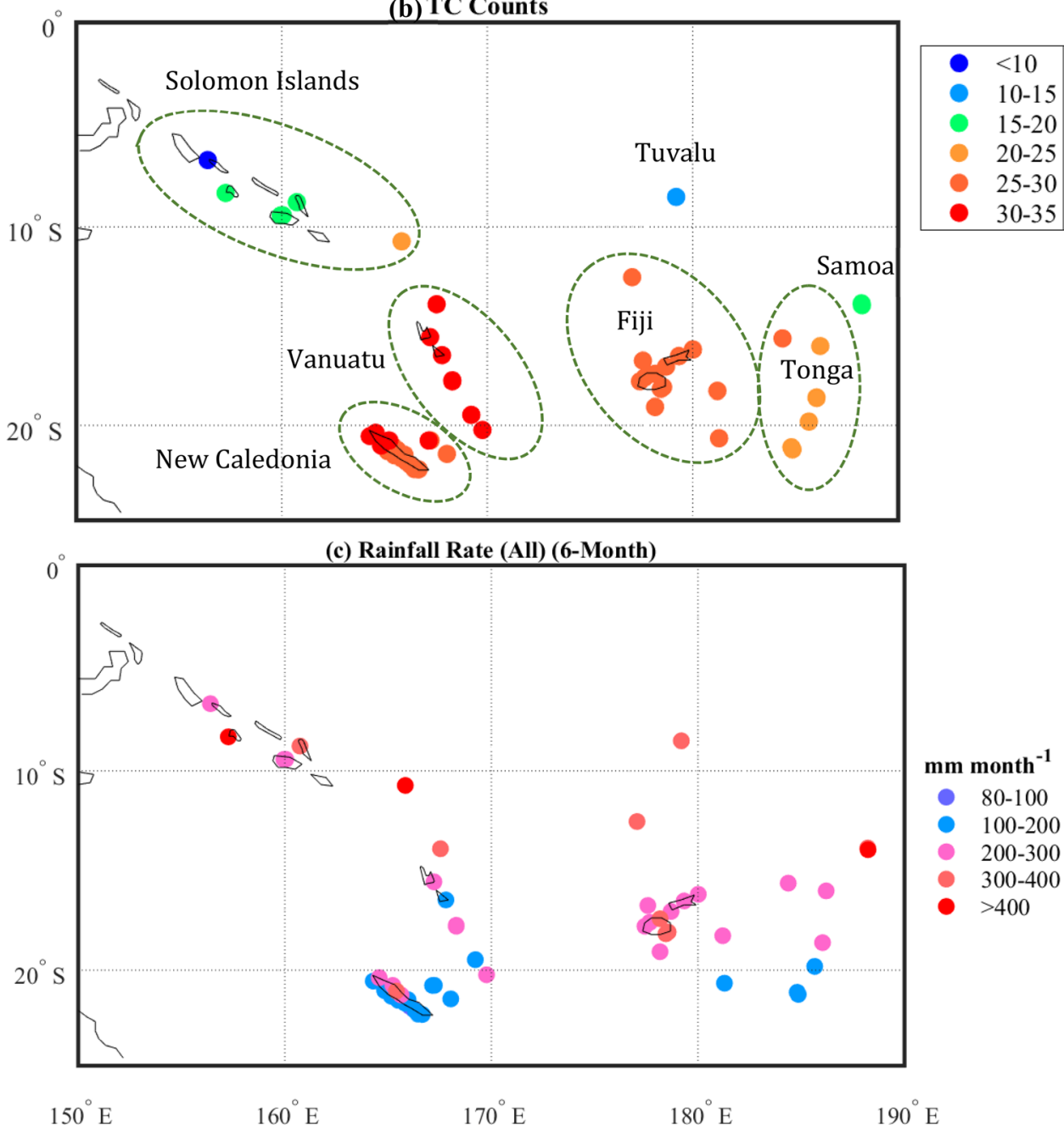

(e.g., Chand and Walsh 2010; Klotzbach 2014; Diamond and Renwick 2015) at the intraseasonal timescale. During the active phase of the MJO (which can be defined using indices such as those of Wheeler and Hendon (2004)), convective activity associated with the SPCZ is enhanced over the SWP region (e.g. Haffke and Magnusdottir 2013). In particular, TCs are typically more frequent and intense over the SWP region during the active phase of the MJO when compared with inactive or weak (i.e. low amplitude) phases (Chand and Walsh 2010; Klotzbach 2014). Seasonally, SWP
TCs are generally observed during the months of November to April with peak activity from January to March when the SPCZ is also more active. However, the passage of the MJO can substantially modulate within-season TC activity as described above.

At the interannual time scale, the El Niño-Southern Oscillation (ENSO; e.g., Trenberth 1997; McPhaden et al. 2006) is a major driver of the SPCZ and TC spatial variability in the SWP basin. During El Niño events, the SPCZ and associated convective activities are displaced farther northeast 
while islands to the southwest often experience lower rainfall (e.g., Karoly and Vincent 1998; Folland et al. 2002; Griffiths et al. 2003). A southwestward shift in the location of the SPCZ and accompanying rainfall, occur during La Niña events. As a result, TC activity is enhanced in the northeast region of the SWP basin during El Niño events, extending across to the Cook Islands and French Polynesia with the greatest incidence around the dateline (e.g., Basher and Zheng 1995; Kuleshov et al. 2008; Chand and Walsh 2009, 2011a, b; Chand et al. 2013; Vincent et al. 2011; Jourdain et al. 2011; Ramsay et al. 2012; Diamond et al. 2013; Dowdy and Kuleshov 2012; Magee et al. 2017). In contrast, the opposite occurs during La Niña events when TC activity is displaced southwestward towards New Caledonia and the Coral Sea with relatively low activity east of about $170^{\circ} \mathrm{E}$. Moreover, the Interdecadal Pacific Oscillation (IPO; e.g., Power et al. 1999) — which is the Pacific-wide manifestation of "ENSO-like" variability at the decadal timescale-also affects SWP climate either directly, for example, through its impact on the SPCZ (e.g., Folland et al. 2002), or indirectly by modulating ENSO teleconnections (e.g., Gershunov and Barnett 1998; Salinger et al. 2001). This has implications for TC activity at interdecadal timescales as well (e.g., Sharma et al. 2019).

From the brief review above, it is clear that TCs in the SWP region can undergo substantial variability at multiple timescales. However, it is less clear how extreme rainfall associated with TCs in this region is influenced by the different modes of variability, and whether TC-induced extreme rainfall has changed over the past few decades. In the SWP Island countries, extreme rainfall events often have severe consequences, particularly those associated with TCs where accompanying destructive winds and storm surges can make emergency responses-and even post-disaster recovery efforts-near impossible for several weeks due to the remote locations of several local communities. Recent studies (e.g., McGree et al. 2014, 2019) have examined the variability and trends in observed total and extreme rainfall over SWP Island countries. They concluded that generally there had been little change in annual and seasonal total and extreme rainfall in the western tropical Pacific in the long-term over the historical record, but there had been significant interannual and decadal variability. In the context of a warming climate, several studies (e.g. Dutheil et al. 2020 and the references therein) report a decrease, in the range of $10 \%$ to $60 \%$, in TC frequency and a consistent intensification of TC-related precipitation under future climate over the SWP region. Some studies (e.g. Yamada et al. 2017; Zhang and Wang 2017) also indicate an increase in the frequency of intense TCs in the future climate over this region. Therefore, a clearer understanding of TC-induced extreme rainfall, and the factors that modulate this connection, is integral for disaster risk mitigation and adaptation planning. It also establishes a baseline for understanding climate change impacts on TC-induced extreme rainfall for the region.

The scope of this paper is twofold. First, we provide improved understanding of the fractional contributions ${ }^{1}$ of seasonal maximum daily rainfall by TCs (hereafter, TCinduced extreme rainfall) in the SWP. Specifically, we examine how these contributions are modulated by various modes of natural climate variability that operate in the region and whether TC-induced extreme rainfall has changed over the past decades-and if so, how? Second, we develop stateof-the-art-statistical models to evaluate the relationships between extreme rainfall (both TC- and non-TC-induced) in the SWP and the combinations of climatic drivers that modulate them. The rest of the paper is organised as follows. Data and analysis methods are described in Sect. 2 (with additional details provided in the Appendix). Section 3 provides results and discussion, followed by Sect. 4 where we present the summary and conclusions.

\section{Data and methodology}

\subsection{TC and rainfall data}

TC data were obtained from the Southwest Pacific Enhanced Archive of Tropical Cyclones (SPEArTC) database (Diamond et al. 2012), which comprises quality assured and collated TC records from the 1840s for the SWP basin. Due to homogeneity issues associated with historical TC records prior to the satellite era (e.g., Landsea et al. 2006; Dowdy and Kuleshov 2012; Kuleshov et al. 2010), only data from July 1970 to June 2019 have been considered in the analyses. Note that TCs in the SWP region are spread over the two calendar years (majority of the TCs occur between November to April), and so a TC season in this study is defined from July 1 of the first year up to June 30 of the following year. For convenience, each season may also be stated using only the first of the two relevant calendar years; for example, the season 1973/1974 may also be referred to as 1973. For the purpose of this study, we objectively define a TC as any system that reaches the 10-min sustained wind speeds of $17 \mathrm{~m} \mathrm{~s}^{-1}$ during any point of its lifetime which is consistent with other studies (e.g. Chand and Walsh 2009). This definition is important as it allows the examination of extreme

\footnotetext{
1 TC contribution here is referred to the ratio of the total number of TC-induced rainfall events (i.e., number of seasons when seasonal maximum rainfall are due to TCs) to the total number of events under consideration (i.e., total number of seasons). Note, as discussed later in the Methods section, TC seasons in the southwest Pacific are spread over the two overlapping seasons (i.e., July to June), and so a season is defined as a period from July of the first year to June of the second year.
} 
rainfall events that are only associated with developed TCs in the SWP, and not weak depressions or disturbances which cause "extreme" rainfall events but are not well-documented in the historical records. Such weak depressions and disturbances are referred to as non-TC events throughout the paper.

Daily rainfall station data for the SWP Island nations were obtained from their respective National Meteorological and Hydrological Services (NMHSs). Only stations that have a near complete record of daily rainfall data since 1970 were included in the analyses; a record is considered near complete if there are observations for a minimum of 330 days in a year (e.g., Villarini and Denniston 2015). Altogether 52 stations satisfied this criterion. We note that daily rainfall data for some stations have undergone quality-control and homogeneity checks as part of previous studies that utilised these station data (e.g., McGree et al. 2014, 2019); the homogenised data are available at the Pacific Climate Change Data Portal (PCCDP 2020; http://www.bom.gov.au/ climate/pccsp/). We also note that rainfall observations at some secondary observation sites may not fully account for rainfall received during a TC event. This may, for example, be due to a MkII 5" manual gauge (inner can capacity of $200 \mathrm{~mm}$ ) overflowing or a $0.2 \mathrm{~mm}$ tipping bucket mechanism of a TB3 rain gauge not fully capturing rainfall during a high intensity event. We acknowledge variation in observing equipment and observer skill across the study region which may present spatial inconsistencies. Since our emphasis is on extremes, further statistical tests are performed for each station time series to detect the presence of any artificial discontinuities in the parameters of interest (i.e., block maxima and peak-over-threshold values in our case). In particular, we implement two widely used nonparametric tests in this study (e.g., see Villarini et al. (2011), and references therein): Pettitt test to detect abrupt changes in the time series and Mann-Kendell test to determine presence of any monotonically increasing or decreasing patterns. Note that the Pettitt test is sensitive to data distributional assumptions and therefore can be inefficient in detecting breaks associated with extremes (Mallakpour and Villarini 2016). Thus, we utilise results from our Bayesian analysis as well to validate results of the Pettitt test (see Appendix). We are also cautious of slowly varying, physically based changes in the time series of extreme rainfall as they can be considered another mode of nonstationarity (e.g., Villarini et al. 2009), and so the time series of each station were visually verified for clarity. Overall, none of our station data exhibited any significant monotonic trends or change-points (at the 5\% significance level) and are free of slowly varying changes in the time series of extremes (see subsequent discussions), and therefore deemed appropriate for the analyses. To further investigate the long-term trends in TC contributions, the National Centre for Environmental Prediction (NCEP)
Reanalysis data (Kalnay et al. 1996) were also utilised. These data were obtained from the National Oceanic and Atmospheric Administration (NOAA) online portal (https ://psl.noaa.gov/data/gridded/data.ncep.reanalysis.pressure. $\mathrm{html})$. In addition to that, the Global Precipitation Climatology Project (GPCP: Adler et al. 2017; Huffman et al. 2001) daily precipitation analysis were also utilised here to obtain the mean rainfall climatology for each MJO phase over the SWP region.

\subsection{Measures of TC-induced extreme rainfall}

Our emphasis is on extreme rainfall due to TCs, and so we have utilised the two widely used measures of TC-induced extreme rainfall in this work: a block maxima approach and peaks-over-threshold (POT) approach. The block maxima approach encompasses the maximum 1-, 2- and 3-day ${ }^{2}$ (e.g., Villarini and Denniston 2015) rainfall events recorded for each TC season (12 months July-June) over the period under consideration (hereafter, seasonal 1-, 2- and 3-day rainfall maximum, respectively). If the event occurred at the time of passage of a TC-defined as the presence of the centre of a named cyclone within a $500-\mathrm{km}$ radius $^{3}$ of a station under consideration during a time window of \pm 1 day (e.g., Villarini and Denniston 2015; Khouakhi et al. 2017) — then that rainfall event was considered as TC-induced rainfall. Following, for example, Villarini and Denniston (2015), we define the 'TC contribution' as the ratio of the total number of TC-induced rainfall events (i.e., number of seasons when seasonal maximum rainfall are due to $\mathrm{TC}$ ) to the total number of events under consideration (i.e., total number of seasons).

It is important to note that the block maxima approach can have limitations, particularly with respect to extreme rainfall in the Pacific where non-TC events can occasionally

\footnotetext{
2 Block maxima approach here consists of first grouping daily rainfall data into specified blocks for each season and then extracting the maximum value of the rainfall for that season. For 1-day block maxima, for example, we extract the maximum value of daily accumulated rainfall for each season. Similarly for 2-day (3-day) block maxima, consecutive days are first summed to create a pool of 2-day (3-day) accumulated rainfall and then the maximum value is extracted for each season. Note that we prefer the term "seasonal maximum" as opposed to "annual maxima" as TC seasons in the southwest Pacific are spread over the two overlapping seasons (i.e., July to June).

3 The choice of 500-km radius is consistent with that of several past studies (e.g., Rodgers et al. 2000; Larson et al. 2005; Lau et al. 2008; Dare et al. 2012; Khouakhi et al. 2017). This estimate may be slightly conservative for TCs in the southwest Pacific where some systems can be larger (e.g., Chavas et al. 2016). Without carrying out the time-consuming task of subjectively examining satellite images of individual TCs to determine their size, we use $500-\mathrm{km}$ as the bounding radius as it is likely to result in a conservative estimate of TC rainfall rather than an overestimate.
} 
account for seasonal maximum (e.g., McGree et al. 2010, 2014, 2019). In such cases, this method alone is not adequate to capture all TC-induced rainfall as it allows only one maximum value per season and discards other values which might otherwise be attributable to TCs. We additionally utilise the POT approach, where we include all values above a particular threshold. A number of methods have been suggested on how to determine thresholds for extreme rainfall (e.g., Coles 2001). In our case, we obtain the thresholds of daily and multi-day totals associated with the 95th percentile using the generalised extreme value (GEV) distribution. The GEV method is a well-established statistical framework and has been successfully applied in several similar studies (e.g., Chu et al. 2009; Villarini et al. 2011; Villarini and Denniston 2015).

After identifying extreme rainfall events using both block maxima and POT approaches, each event was then binned into their respective MJO and ENSO phases that operated at the time of occurrence of the event. The MJO phases were obtained from the Australian Bureau of Meteorology website (BOM 2020; refer to Wheeler and Hendon (2004) for methodological details). For convenience, we grouped consecutive phases of the MJO together such that the active phases of the MJO in the SWP are those associated with groups 6 and 7 (MJO 6-7), and groups 8 and 1 (MJO 8-1) whereas the inactive phases are groups 2 and 3 (MJO 2-3), and groups 4 and 5 (MJO 4-5). In addition to these, cases where the MJO amplitude was less than one were grouped into the weak phase. The ENSO phases used here are those readily available from the Climate Prediction Centre website (CPC 2020). Each event was grouped into either El Niño, La Niña or neutral phase based on the Oceanic Niño Index (ONI) for the months of December-February (see Trenberth (1997) for details on ENSO classification).

\subsection{Statistical significance of TC contributions}

Statistical significance of the TC-induced extreme rainfall contribution (against the null hypothesis of zero contribution as not all TCs in the Pacific contribute to seasonal maximum as discussed later) was evaluated using a non-parametric bootstrap resampling method (e.g., Efron and Tibshirani 1991). Here the Monte Carlo algorithm was used to resample data - with replacement-from a pool of original data, maintaining the size of resampled data to that of the original data. Resampling was repeated for a total of 1000 iterations, and the ratios of TC-contributions $(\rho)$ were calculated for each iteration, yielding a total of 1000 values. The two hypotheses (H0: $\rho=0 ; \mathrm{H} 1: \rho>0)$ were then evaluated at the 5\% significance level $(\alpha=0.05)$; TC-contributions are deemed statistically significant if $\rho_{\alpha=0.05}$ (which corresponds to the $5^{\text {th }}$ percentile of 1000 bootstrapped values) is greater than zero. Similarly, statistical significance of the difference between two independent data were obtained by comparing their $95 \%$ bootstrapped confidence intervals; non-overlapping intervals are indicative of statistically significant differences.

\subsection{Bayesian model for TC-induced rainfall probabilities}

We developed probit regression models ${ }^{4}$ using Bayesian fitting (e.g., Chand and Walsh 2011b, 2012) to evaluate the relationships between extreme rainfall and the combinations of various climatic drivers (MJO, ENSO and IPO) that modulate them. Such models can be used to assess probabilities of extreme rainfall for cases when, for example, one or more climatic drivers are favourable at the time of a TC. They can also help examine differences in probabilities between TCand non-TC-induced extreme rainfall events.

We first determined the largest 1-day rainfall value for each season (i.e., seasonal maximum daily rainfall). Each seasonal maximum daily rainfall was then classified accordingly into respective binary classes of " $0 \mathrm{~s}$ " and " $1 \mathrm{~s}$ " depending on whether the value exceeded the median threshold or not, yielding a time series of binary response variable for the station under consideration. The median rainfall corresponds to the 50th percentile of seasonal maxima for a particular station over the period under consideration. We then explored the state of the drivers (or predictors) associated with each seasonal maximum daily rainfall event: the presence of a TC, and the phases of the MJO, ENSO and IPO at the time of the event. Finally, we developed probit regression models as outlined below in the context of our analysis (reader is referred to Albert and Chib (1993) for mathematical formulations of probit regression models). For-ease-ofinterpretation, we focus on selected stations having records of past TC incidences that caused substantial damages to local communities in terms of extreme rainfall and flooding.

Let $y_{i}$ be a response variable such that $y_{i}=1$ when the value of seasonal maximum daily rainfall exceeds the median for the $i$ th season $\left(y_{i}=0\right.$ otherwise). If there exists an independent normally distributed latent variable $\boldsymbol{Z}_{i}$ such that

\footnotetext{
${ }^{4}$ Determining whether the probability of an event will exceed a particular threshold or not, conditional upon a set of predictor variables, is an example of a binary classification problem. Probit regressions can be considered a proper probability model for describing such binary response data. We use the Bayesian technique (as opposed to frequentist approach such as least square or maximum likelihood) to determine model parameter coefficients of our probit models. The Bayesian technique assumes that model parameters are not fixed but have a distribution. Therefore, inferences can be made by computing posterior probability density estimates of model parameters conditioned on the observed data (extreme rainfall in our case). The posterior distributions can then be used to make predictive inferences within a probabilistic framework.
} 
$\mathbf{Z}_{i}=X_{i} \beta^{\prime}+\varepsilon_{i}, \varepsilon_{i} \sim N(0,1) ; i=1, \ldots, N$,

then for each season $i$, we define a binary class label $y_{i}=1$ if $Z_{i} \geq 0$ and $y_{i}=0$ if $Z_{i}<0$. Here $\beta$ represents the model coefficient associated with the respective predictor variable $X_{i}$ and $\varepsilon_{i}$ is an error term assumed to have a standard normal distribution with a mean of zero and variance of one. The predictor variable $X_{i}$ (which can be either binary or continuous) and the associated coefficient parameter vector $\beta$ over a total of $N$ years are specified as follows:

$X_{i} \in\left\{1, T C_{i}, M O_{i}, E N S O_{i}, I P O_{i}\right\} ; i=1,2, \ldots, N$,

$\beta \in\left\{\beta_{0}, \beta_{T C}, \beta_{M J O}, \beta_{E N S O}, \beta_{I P O}\right\}$.

The values of predictor $T C_{i}=1$ if a TC is present $\left(T C_{i}=0\right.$ otherwise). Similarly, $M J O_{i}=1$ if the event coincided with the active phases and $M J O_{i}=0$ if the event occurred during an inactive phase; the phases of the MJO are defined following Wheeler and Hendon (2004). The ONI is those from the CPC (2020) and the IPO index, which is a measure of interdecadal variability, is from Henley et al (2015).

The value of $Z_{i}$ is not known as the exact posterior distribution of regression parameter $\beta$ is not known. However, given the data $y_{i}$, the posterior distribution of the regression parameter can be simulated in the Bayesian framework using a widely used Markov Chain Monte Carlo (MCMC) approach called the Gibbs sampler (Gelfand and Smith 1990, see also Appendix A1 for details). Thus, the values of $Z_{i}$, and hence the corresponding binary class label variable $Y_{i}$, can be obtained from the truncated normal distribution (e.g., Albert and Chib 1993) such that

$Z_{i} \mid y_{i}, \beta \sim N\left(X_{i}^{T} \beta, 1\right)$

truncated at the left by 0 if $y_{i}=1$ and,

$Z_{i} \mid y_{i}, \beta \sim N\left(X_{i}^{T} \beta, 1\right)$

truncated at the right by 0 if $y_{i}=0$.

The probability of rainfall exceeding a particular threshold $P\left(y_{i}=1\right)$, or not $P\left(y_{i}=0\right)$, can then be expressed as

$P\left(y_{i}=1\right)=\frac{1}{L} \sum_{i=1}^{L} Y_{i}$,

$P\left(y_{i}=0\right)=1-P\left(y_{i}=1\right)$,

where $L$ is the number of iterations of the Gibbs sampler ( $L=5000$ in our case).

Validity of several statistical assumptions, including model convergence and stationarity, are inferred from various diagnostics available within the Bayesian framework.
For example, model convergence is inferred from the Gelman and Rubin (1992) diagnostics where different initial conditions are utilised for various chains of MCMC simulation. After convergence, posterior distributions of all chains reach a similar steady state (Appendix A2). In our case, the convergence occurs at around 2000 iterations, and so we discard the first 2000 iterations as "burn-in" and use the subsequent 5000 iterations to obtain posterior density distributions of our model parameters. Model parameters can also be used to determine the validity of the stationarity assumption (which indicates that statistical properties of a variable do not change with time). The slow decay of autocorrelation function derived from model parameters often indicates non-stationarity (e.g., Elsner et al. 2008). In our case, the autocorrelation values associated with each model parameter reaches zero fairly quickly, indicating no violation of the stationarity assumptions (Appendix A2).

The overall skill of our probit model for each station is assessed using the leave-one-out cross-validation (LOOCV) technique (e.g., Elsner and Schmertmann 1994). The LOOCV technique works by successively omitting each season's observation and repeating the modeling procedure to predict the omitted observation, with the resulting " "prediction" often referred to as the "'hindcast'. Statistical measures of categorical statistics such as contingency table, bias scores and Hansen-Kuipers scores (e.g., McBride and Ebert 2000) are derived from the hindcasts to evaluate model performances for each station (Appendix A3).

\section{Results and discussion}

\subsection{Seasonal contributions}

Figure 1b shows the occurrences of TCs per decade (that appeared within $500 \mathrm{~km}$ from each station) for each station during the study period; TC occurrences vary with latitude. Fewer than 15 TCs passing within $500 \mathrm{~km}$ occur for stations equatorward of $10^{\circ} \mathrm{S}$ (such as the Solomon Islands) where TC formations are rare (e.g., Chand and Walsh 2009) compared to the regions poleward of $10^{\circ} \mathrm{S}$ (such as Vanuatu, Fiji, Samoa, New Caledonia and Tonga) where TC occurrences range between 15-35 per decade. Figure 1c further shows the overall (i.e. including TCs and non-TCs) average rainfall rate per month over the SWP nations for the November to April season for the period 1970-2018. The monthly rainfall rate during this season tends to be larger than $200 \mathrm{~mm}$ for regions mostly equatorward of $20^{\circ} \mathrm{S}$. Over New Caledonia and Fiji, an east-west difference is also present: rainfall rate tends to be larger on the eastern-board (north eastern for the case of New Caledonia) than that over the western-board.

The fractional TC contributions to 1-, 2- and 3-day seasonal maximum daily rainfall show a large regional-scale 

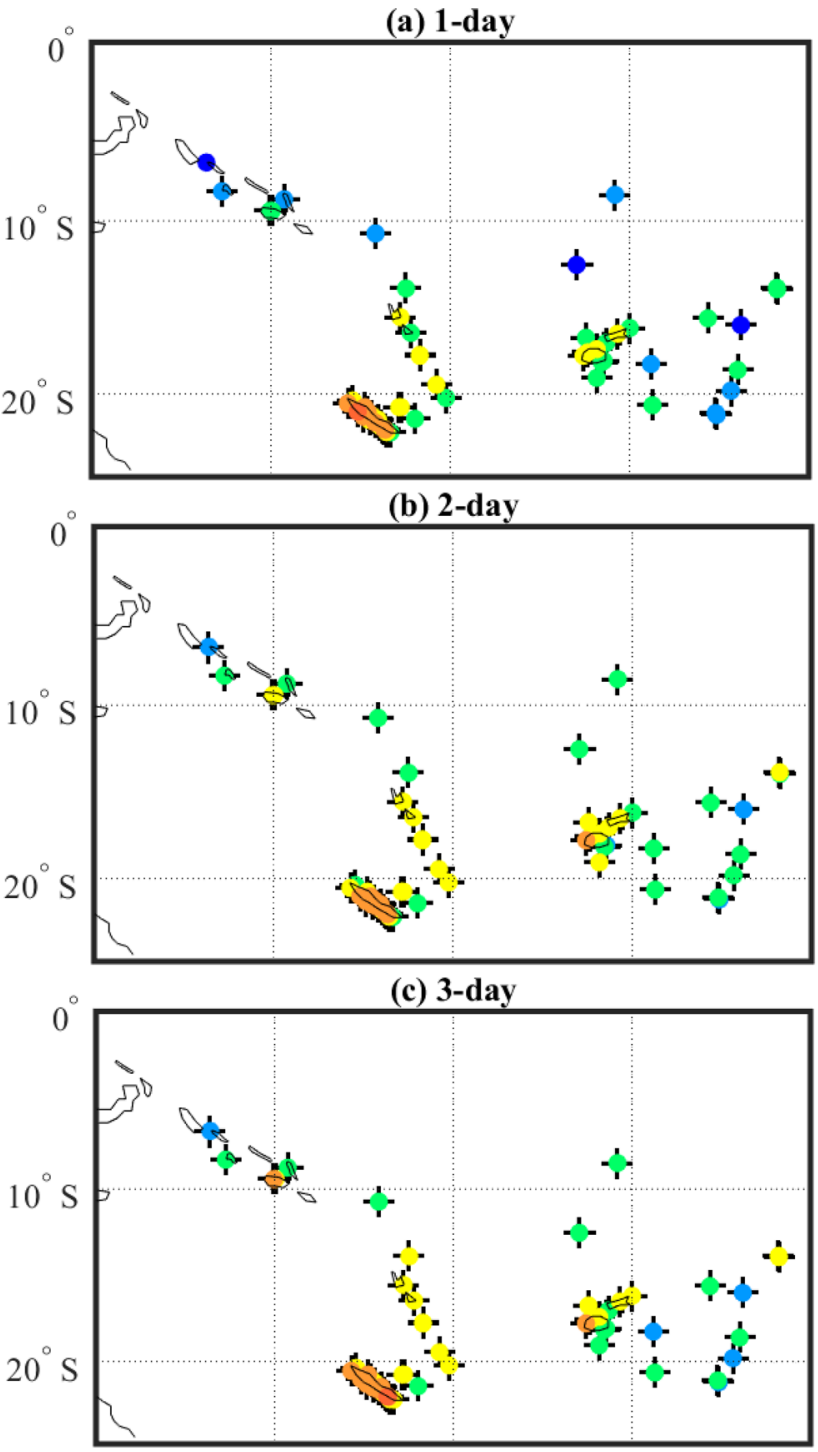

$$
\begin{aligned}
& 150^{\circ} \mathrm{E} \quad 160^{\circ} \mathrm{E} \quad 170^{\circ} \mathrm{E} \quad 180^{\circ} \mathrm{E} \quad 190^{\circ} \mathrm{E} \\
& \text { - } 0-10 \% \quad-10-20 \% \quad \bullet \quad 20-30 \%
\end{aligned}
$$

Fig. 2 Maps showing the contribution of TCs to 1-, 2- and 3-day seasonal maximum daily rainfall $(\mathbf{a}-\mathbf{c})$ as well as for rainfall exceeding the 95th percentile threshold ( $\mathbf{d}-\mathbf{f}$ the threshold is computed using the

variability (Fig. 2a-c). The larger contributions are generally over New Caledonia with some stations recording $>50 \%$ contributions, indicating that more than half of the seasonal maximum daily rainfall over this region is associated with TC passages. TC-induced contributions for Fiji and Vanuatu are also substantial (i.e., $30-40 \%$ ). Table 1 provides a summary (i.e. average) of 1-, 2- and 3-day TC contribution to seasonal maximum rainfall for the different nations. It shows that Tonga has the weakest contribution followed by (in an increasing order when considering the 2 and 3-day (d) 1-day:P95

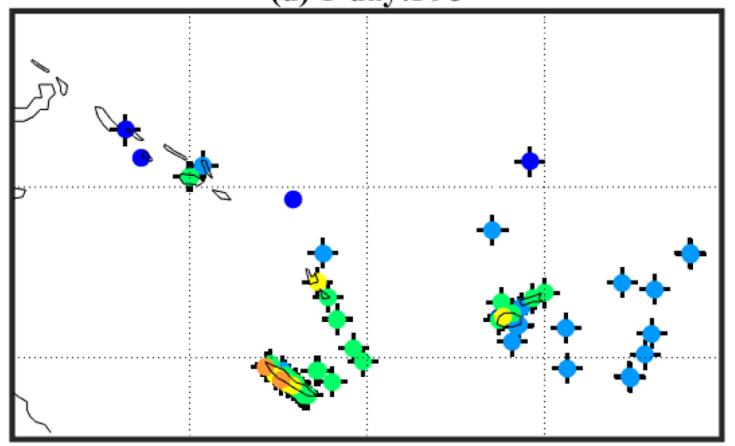

(e) 2-day:P95

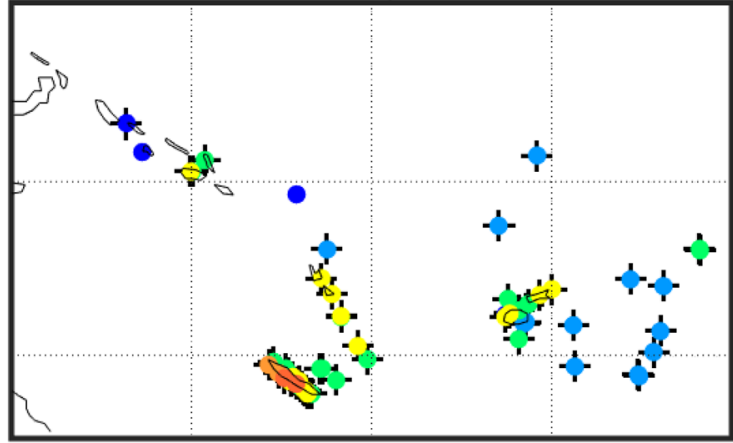

(f) 3-day:P95

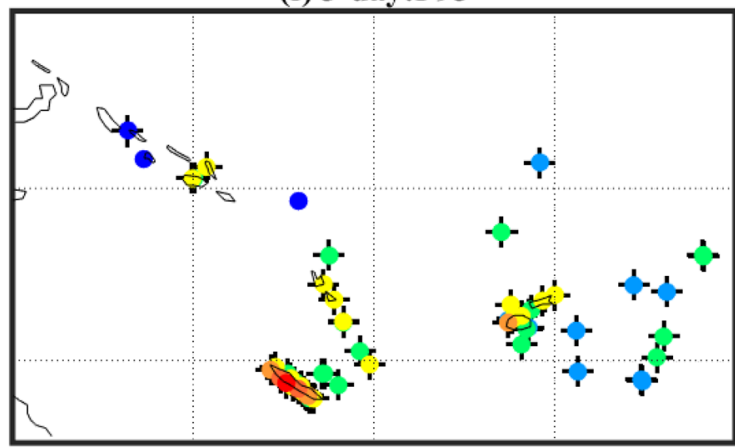

generalised extreme value theorem). The crosses denote the percentages that are statistically different from zero at the 5\% significance level

percentages) Tuvalu, Solomon Islands, Fiji, Samoa, Vanuatu and New Caledonia.

It is important to note that the TC contributions over most stations and regions (Fig. 2 and Table 1) increase as the accumulation period (or days) increases. This is because TCs are often relatively slow-moving synoptic weather systems with large spatial extent in comparison to thunderstorm activities, and therefore are likely to contribute substantial amounts of rainfall in a particular region over a period of time. Also, TCs have strong rainfall rates, and thus, when 
Table 1 Average 1-,2- and 3-day TC contribution to seasonal maximum rainfall

\begin{tabular}{lllll}
\hline Country & 1 Day (\%) & 2 Day (\%) & 3 Day (\%) & $\begin{array}{l}\text { \% change (3-1 } \\
\text { Day)/1 Day }\end{array}$ \\
\hline Tonga & 16.52 & 20.43 & 20.59 & 24.69 \\
Tuvalu & 19.15 & 21.28 & 21.74 & 13.53 \\
Solomon Islands & 17.66 & 25.14 & 25.14 & 42.33 \\
Fiji & 24.93 & 28.98 & 29.95 & 20.17 \\
Samoa & 22.76 & 31.10 & 30.31 & 33.14 \\
Vanuatu & 31.22 & 34.62 & 34.99 & 12.07 \\
New Caledonia & 38.39 & 37.81 & 40.06 & 4.37 \\
\hline
\end{tabular}

accumulated over 3 days, the chance of having an extreme value is enhanced. The influence of TC translation speed should additionally be taken into consideration as TCs usually stay longer in some regions where they slowly intensify (e.g. Solomon Islands) and pass more rapidly over other regions (e.g. in the more southern part of the study region). This is evident when comparing the 1-day and 3-day TC contribution over different regions (Table 1, column 5) which shows that the percentage change is generally more over nations that are equatorward (e.g. Solomon Islands and Samoa) than those that are poleward (e.g. Vanuatu and New Caledonia).

Figure $2 \mathrm{~d}-\mathrm{f}$ shows the TC contributions to 1-, 2- and 3-day rainfall exceeding the 95th percentile (P95) threshold obtained using an alternative POT approach. Similar to our findings above, TC contributions, in particular over New Caledonia are large (it exceeds $60 \%$ over some stations) suggesting that TCs provide the majority of the extreme rainfall days. It is interesting to note that TC contribution is stronger on the west coast of New Caledonia than on the east coast while rainfall is stronger, on average, in the east coast than in the west coast (see Fig. 1c also). This implies that the west coast rainfall events are mostly associated with TCs, which is not the case for the east coast events. The same applies over Fiji where TC contribution is larger over the western then over the eastern board while rainfall is stronger, on average, in the east coast than in the west coast (see Fig. 1c also).

As outlined earlier, TCs in the SWP region are usually observed during the months of November to April, with peak activity occurring from January to March. Hence, it is useful to examine how TC contributions to extreme rainfall events compare for early, peak and late seasons: early season (October to December, OND), peak season (January to March, JFM) and late season (April to June, AMJ). Figure 3 shows the contribution of TCs to 1-, 2- and 3-day seasonal maximum daily rainfall (column 1) and the contribution of TCs to 1-, 2- and 3-day rainfall exceeding the $95^{\text {th }}$ percentile threshold (column 2) for these "targeted" seasons.
As expected, TC contributions to extreme rainfall are the largest during the peak season of JFM when TC activity also peaks. When considering the seasonal maximum rainfall metric (column 1), the contribution to extreme rainfall counts during this season exceeds $50 \%$, in particular over New Caledonia and Vanuatu, indicating that more than half of the extreme rainfall events over these Island countries are due to peak season TCs. During other non-peak seasons (OND and AMJ), TC contributions are usually $<20 \%$, as anticipated, due to fewer TCs.

Considering the 95th percentile threshold (P95-column 2 ), the TC contribution exceeds $50 \%$ particularly over New Caledonia, Vanuatu and Fiji during JFM. Over New Caledonia, TC contribution over some stations exceeds $70 \%$. This shows that the most intense rainfall over the SWP Island nations-particularly over New Caledonia, Vanuatu and Fiji-are mostly due to TCs.

The positive association between TCs and extreme rainfall has also been reported over other regions. For example, a study by Villarini and Denniston (2015) shows that more than half of the highest annual rainfall events over Australia are associated with TCs over the coastal regions and in particular over the Western Australia. This study further shows that TC fractional contribution to extreme rainfall increases with the largest rainfall events; approximately $66-100 \%$ of annual maximum in excess of $100 \mathrm{~mm}$ over Western Australia associated with TCs at over one third of the locations.

\subsection{Influence of the MJO}

Given that the MJO significantly influences SWP TC activity as discussed earlier, we further examined the relationship between different phases of the MJO and TC-induced extreme rainfall. Our findings (Fig. 4) show considerable variations in TC contribution to seasonal 1-, 2- and 3-day rainfall maximum during different phases of the $\mathrm{MJO}$, with the contributions also varying regionally. During MJO phases $2-3$ and $4-5$, contributions west of $170^{\circ} \mathrm{E}$ are $>50 \%$ (statistically significant) over several stations (even greater than $80 \%$ for some stations). On the other hand, TC contributions are generally $<40 \%$, and even $<20 \%$, for most of them (majority of which are also not statistically significant) for regions east of $170^{\circ} \mathrm{E}$. The peak contributions during these phases are over Vanuatu and New Caledonia. For MJO phases 6-7 and 8-1, TC contributions to extreme rainfall $>50 \%$ are observed mostly over regions poleward of $10^{\circ} \mathrm{S}$, with the highest contributions generally occurring over New Caledonia and Vanuatu for both single and multiday rainfall events. TC contributions over regions east of $170^{\circ} \mathrm{E}$ during these phases are also larger in comparison to those during MJO phases 2-3 and 4-5. During the weak MJO phase, TC contributions are $<50 \%$ over the majority of stations. The contributions during this phase, particularly 
Fig. 3 Maps showing the contributions of TCs to 1-, 2- and 3-day maximum daily rainfall for early (OND), peak (JFM) and late (AMJ) seasons (column 1 ), as well as the contribution of TCs to 1-, 2- and 3-day rainfall exceeding the 95 th (column 2) percentile threshold. The crosses denote the percentages that are statistically different from zero at the 5\% significance level

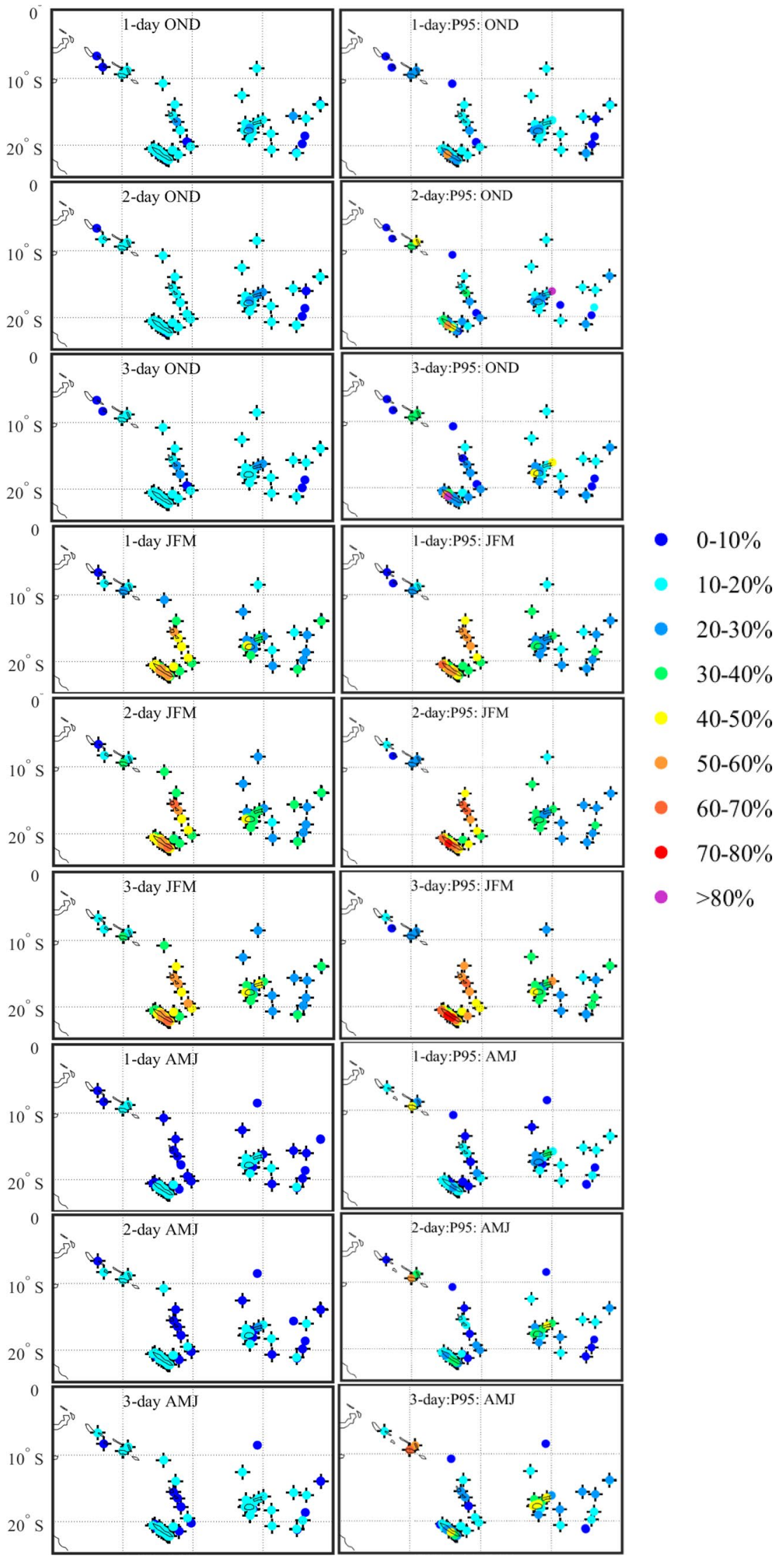




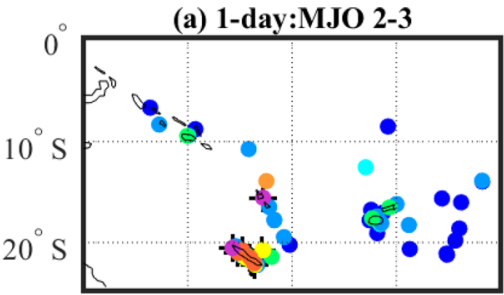

(b) 1-day:MJO 4-5

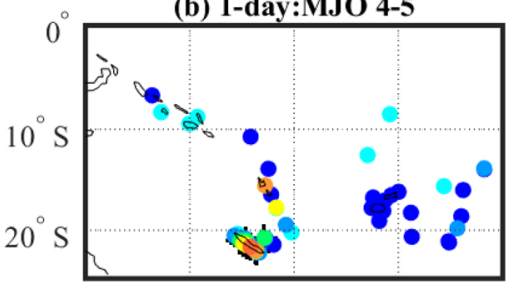

(c) 1-day:MJO 6-7

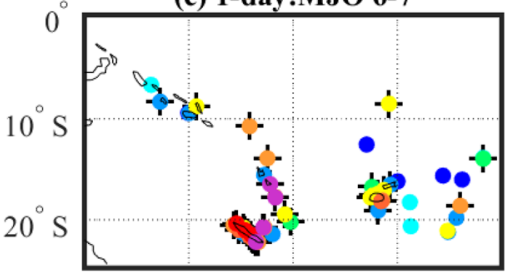

(d) 1-day:MJO 8-1

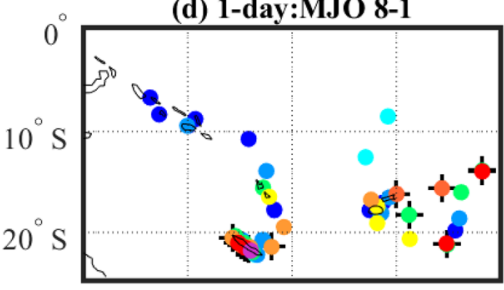

(e) 1-day:MJO Weak

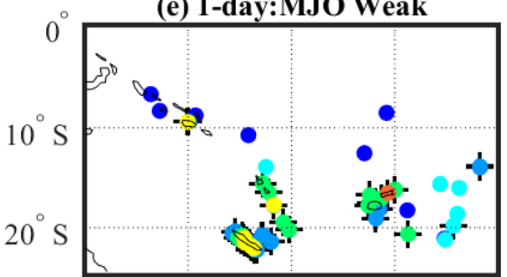

(f) 2-day:MJO 2-3

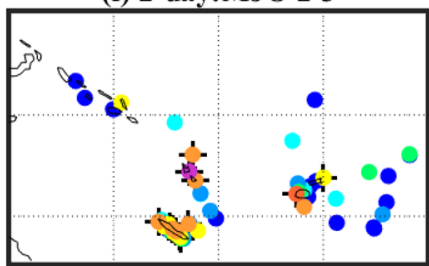

(g) 2-day:MJO 4-5

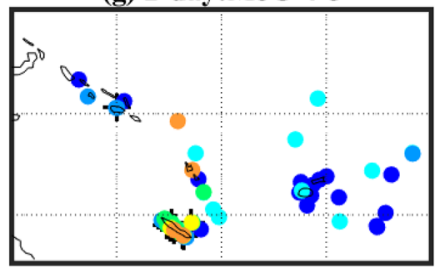

(h) 2-day:MJO 6-7

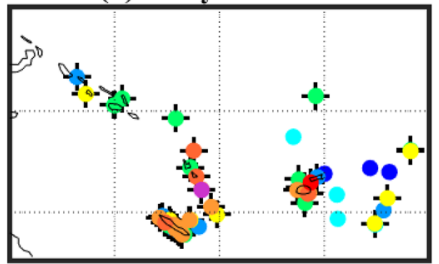

(i) 2-day:MJO 8-1

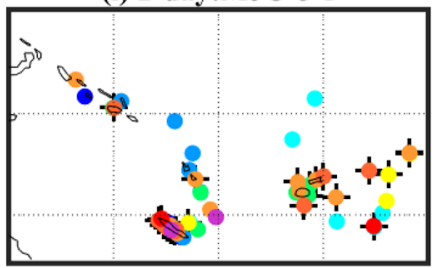

(j) 2-day:MJO Weak

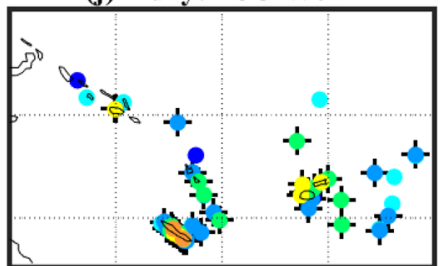

(k) 3-day:MJO 2-3

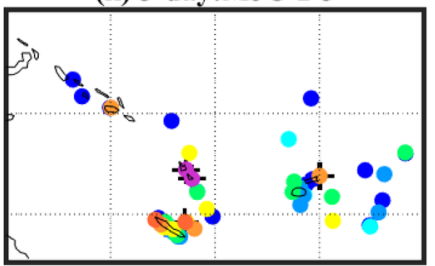

(l) 3-day:MJO 4-5

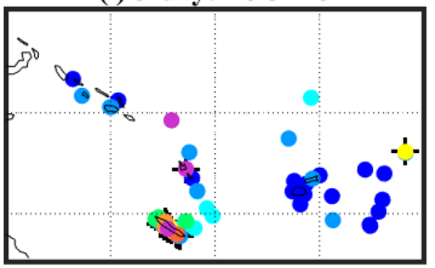

(m) 3-day:MJO 6-7

$0-10 \%$

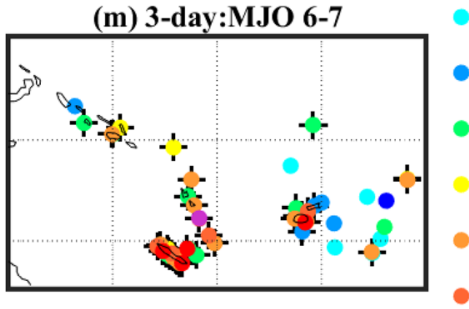

$10-20 \%$

$20-30 \%$

$30-40 \%$

$40-50 \%$

$50-60 \%$

$60-70 \%$

(n) 3-day:MJO 8-1

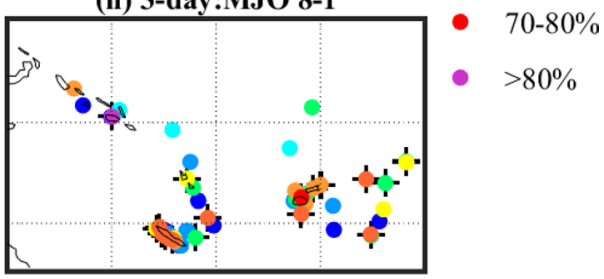

(o) 3-day:MJO Weak

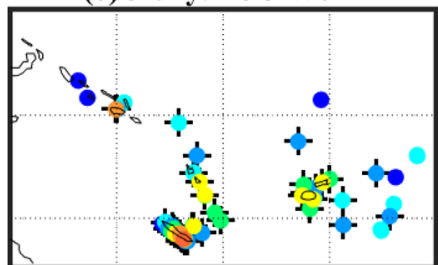

$150^{\circ} \mathrm{E} \quad 160^{\circ} \mathrm{E} \quad 170^{\circ} \mathrm{E} \quad 180^{\circ} \mathrm{E} \quad 190^{\circ} \mathrm{E} 150^{\circ} \mathrm{E} \quad 160^{\circ} \mathrm{E} \quad 170^{\circ} \mathrm{E} \quad 180^{\circ} \mathrm{E} \quad 190^{\circ} \mathrm{E} 150^{\circ} \mathrm{E} \quad 160^{\circ} \mathrm{E} \quad 170^{\circ} \mathrm{E} \quad 180^{\circ} \mathrm{E} \quad 190^{\circ} \mathrm{E}$

Fig. 4 Maps showing the contribution of TCs to 1-, 2- and 3-day maximum rainfall during the different phases of MJO. The crosses denote the percentages that are statistically different from zero at the $5 \%$ significance level

east of $170^{\circ} \mathrm{E}$, however, are generally greater than those during the inactive phases (2-3-4-5), It should also be noted here that there are local differences in the percentage contributions (such as the close presence of blue and red dots) during the different phases but the reasons for this is not clear at present.

These findings can be attributed to the suppression and enhancement of large-scale convective activity that influences TC activity during different phases of the MJO. The MJO tends to be active over the SWP region during phases 6 , 7, 8 and 1 and inactive during phases 2, 3, 4 and 5 (Wheeler and Hendon 2004). During the active phase of the MJO, convective activity associated with the SPCZ is enhanced over the SWP region (e.g. Haffke and Magnusdottir 2013). Hence, TCs are relatively more frequent (see normalised frequency of TCs in Fig. 5c, d) and more intense during active phases of the MJO when compared with inactive or weak phases (Fig. 5a, b, e) (Chand and Walsh 2010; Leroy et al. 2008; Klotzbach 2014; Ramsay et al. 2012). Differences in TC frequency between the active and inactive phases of the MJO are evaluated here in order to determine if the differences in TC-induced extreme rainfall between these two 


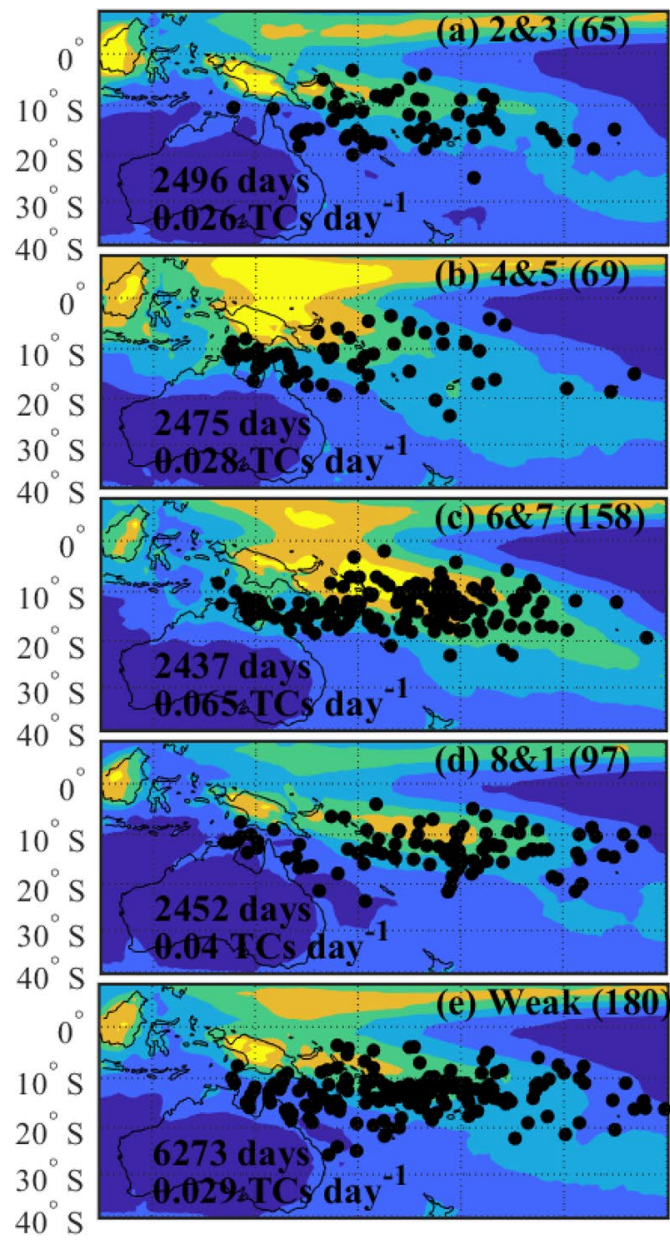

$120^{\circ} \mathrm{E} 140^{\circ} \mathrm{E} 160^{\circ} \mathrm{E} 180^{\circ} \mathrm{E} 200^{\circ} \mathrm{E} 220^{\circ} \mathrm{E}$

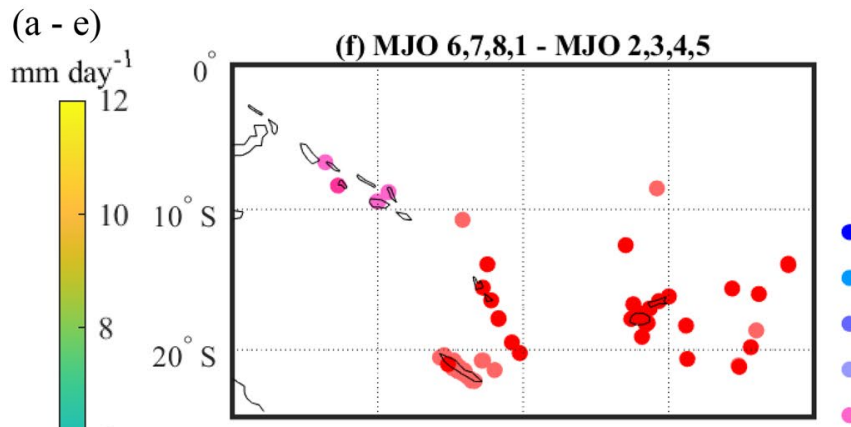

(f - g)

$<-30 \%$

$-30--20 \%$

$-20--10 \%$

$-10-0 \%$

$0-10 \%$

$-6$

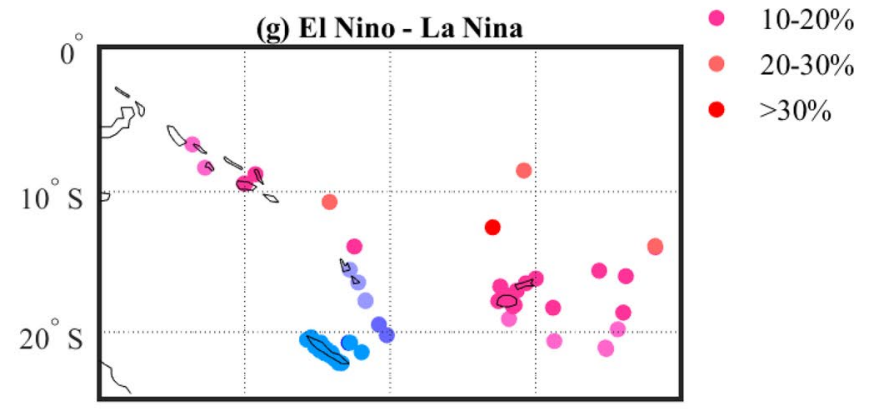

$150^{\circ} \mathrm{E} \quad 160^{\circ} \mathrm{E} \quad 170^{\circ} \mathrm{E} \quad 180^{\circ} \mathrm{E} \quad 190^{\circ} \mathrm{E}$
Fig. 5 a-e Maps showing TC genesis locations (dots) and the number of TCs (in brackets) according to the phases of the MJO. Included are also the number of days for which the MJO phase occurred and the number of TCs relative to the number of days (i.e. normalised frequency of TCs denoted as TCs day ${ }^{-1}$ ) for each MJO phase. The back-

generalised active and inactive phases are indeed linked to each other (Fig. 5f). It is evident that TC occurrences during active phases of the MJO are larger than during inactive and weak phases, as reported in previous studies (Leroy et al. 2008; Chand and Walsh 2010; Ramsay et al. 2012; Klotzbach 2014). Therefore, it is highly likely that the relatively larger contribution of TCs to extreme rainfall during the active phase of the MJO, as opposed to the inactive phase, is simply because there are more TCs.

\subsection{Influence of ENSO}

We next examined the relationship between ENSO and TCinduced extreme rainfall for the SWP (Fig. 6). Results show that TC contributions to seasonal 1-, 2- and 3-day rainfall maximum are considerably influenced by ENSO. During ground is the mean precipitation pattern for each MJO phase obtained using the GPCP data. Differences in TC occurrences over each station between the MJO active (MJO 6, 7, 8, 1) and inactive (MJO 2, 3, 4, 5) phases, and between El Niño and La Niña events for the periods 1970-2018 are also shown in (f) and (g) respectively

La Niña (Fig. 6a, e, i), TC contributions are larger over regions west of $170^{\circ} \mathrm{E}$, particularly over New Caledonia and Vanuatu, where contributions can exceed 50\% for some stations. For regions east of $170^{\circ} \mathrm{E}$, TC contributions are generally $<40 \%$. During ENSO Neutral years (Fig. 6b, f, j), TC contributions somewhat decrease for regions equatorward of $15^{\circ} \mathrm{S}$, but increase for regions poleward of $15^{\circ} \mathrm{S}$ and between $160-180^{\circ} \mathrm{E}$ (i.e., over New Caledonia and Fiji where contributions are $>60 \%$ ). During El Niño events (Fig. 6c, g, k), TC contributions increase over Vanuatu and in the regions east of $170^{\circ} \mathrm{E}$ with the maximum contributions exceeding $50 \%$ over Fiji. In essence, larger contributions (i.e. $>50 \%$ ) systematically shift towards the eastern parts of the SWP as the phase of ENSO changes from La Niña to El Niño (see also Fig. $6 \mathrm{~d}, \mathrm{~h}, \mathrm{l})$. These changes are consistent with increased $\mathrm{TC}$ activity in the region east of $170^{\circ} \mathrm{E}$ during El Niño as 


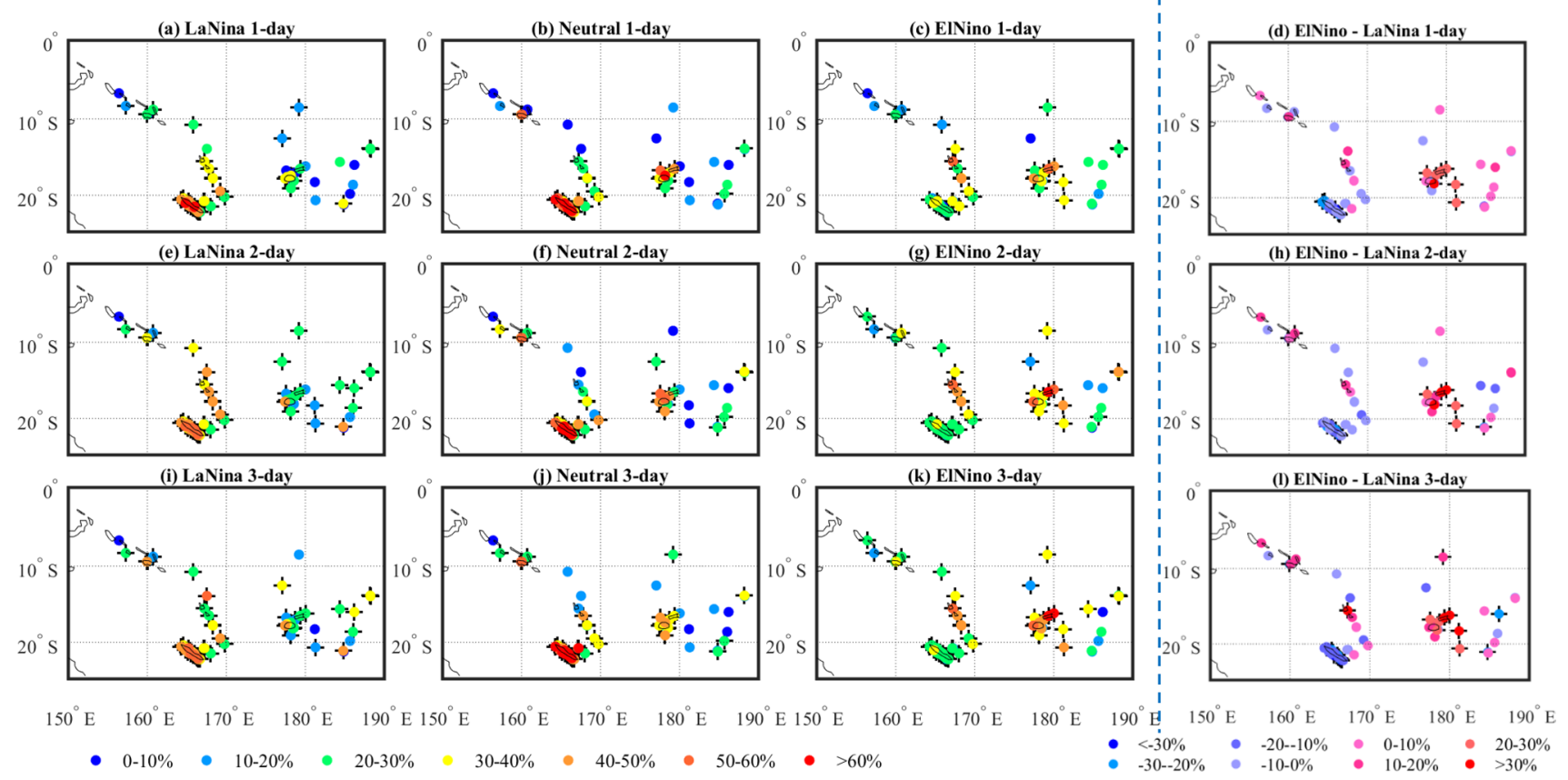

Fig. 6 Maps showing the contribution of TCs to 1-, 2- and 3-day seasonal maximum daily rainfall during the different phases of ENSO: La Niña-column 1, Neutral-column 2 and El Niño-column 3. Column 4 shows the difference in the percentages between El Niño

opposed to La Niña years (Fig. 5g). The above findings are also consistent with that reported over Australia, which lies west of the SWP region. Studies by Villarini and Denniston (2015) and Khouakhi et al. (2017) show that, over Australia, larger probability of TC-related annual maximum rainfall occurs during La Niña years.

\subsection{Long-term changes in TC-induced extreme rainfall}

On average, TC numbers are likely to decrease in a warming climate, but their intensities are likely to increase (e.g., see Knutson et al. (2019) and Dutheil et al. (2020) for a review). The latter translates to an increase in the magnitude of extreme rainfall events associated with TCs. Here, we investigate whether TC contributions to extreme rainfall events have changed over recent decades, and if so, how? Fig. 7 shows the difference in TC contribution to 1-, 2- and 3-day rainfall maximum between the periods 1994-2018 and 1970-1993 for early, peak and late TC seasons (i.e., OND, JFM, and AMJ respectively). Overall, we find a slight increase in TC contributions during AMJ, and to some extent during OND, whereas the contribution generally decreases during JFM. During OND, TC contribution generally decreases over New Caledonia and Vanuatu (by more than $30 \%$ over some stations). However, a slight increase is observed over the Solomon Islands and regions east of and La Niña years. The crosses denote the percentages that are statistically different from zero at the 5\% significance level. Note that column 4 has a separate colour scale

$170^{\circ} \mathrm{E}$ (mostly less than $10 \%$ increase). During JFM, there is an overall decrease in TC contribution for the majority of stations, but the decrease is more prominent over regions west of $\sim 185^{\circ} \mathrm{E}$ (especially over Vanuatu and Fiji). For regions east of $185^{\circ} \mathrm{E}$ (i.e. Tonga and Samoa), TC contribution tends to increase (in excess of $30 \%$ over some stations). During AMJ, TC contribution increases slightly for most of the stations, especially for multi-day events ( $\sim 0$ to $10 \%$ increase).

One of the important factors to the difference in TC contributions observed above could be linked to changes in the frequency of occurrences of TCs between the two periods under consideration (Fig. 8). Overall, TC numbers have decreased in the latter period, particularly over regions west of $185^{\circ} \mathrm{E}$, although there is a slight increase over regions east of $185^{\circ} \mathrm{E}$. The decrease in $\mathrm{TC}$ numbers west of $185^{\circ} \mathrm{E}$ could explain the observed decrease in TC contributions to extreme rainfall events over this region (particularly during JFM). Similarly, the increase in TC contribution east of $185^{\circ} \mathrm{E}$ could be related to the increase in TC occurrences over this region.

We note that even though TC contributions to extreme rainfall events have decreased over most of the SWP region due to a decrease in TC occurrences over the past few decades (as discussed above), it appears that the intensity of extreme rainfall events associated with individual TCs have somewhat increased (though not statistically significant at 

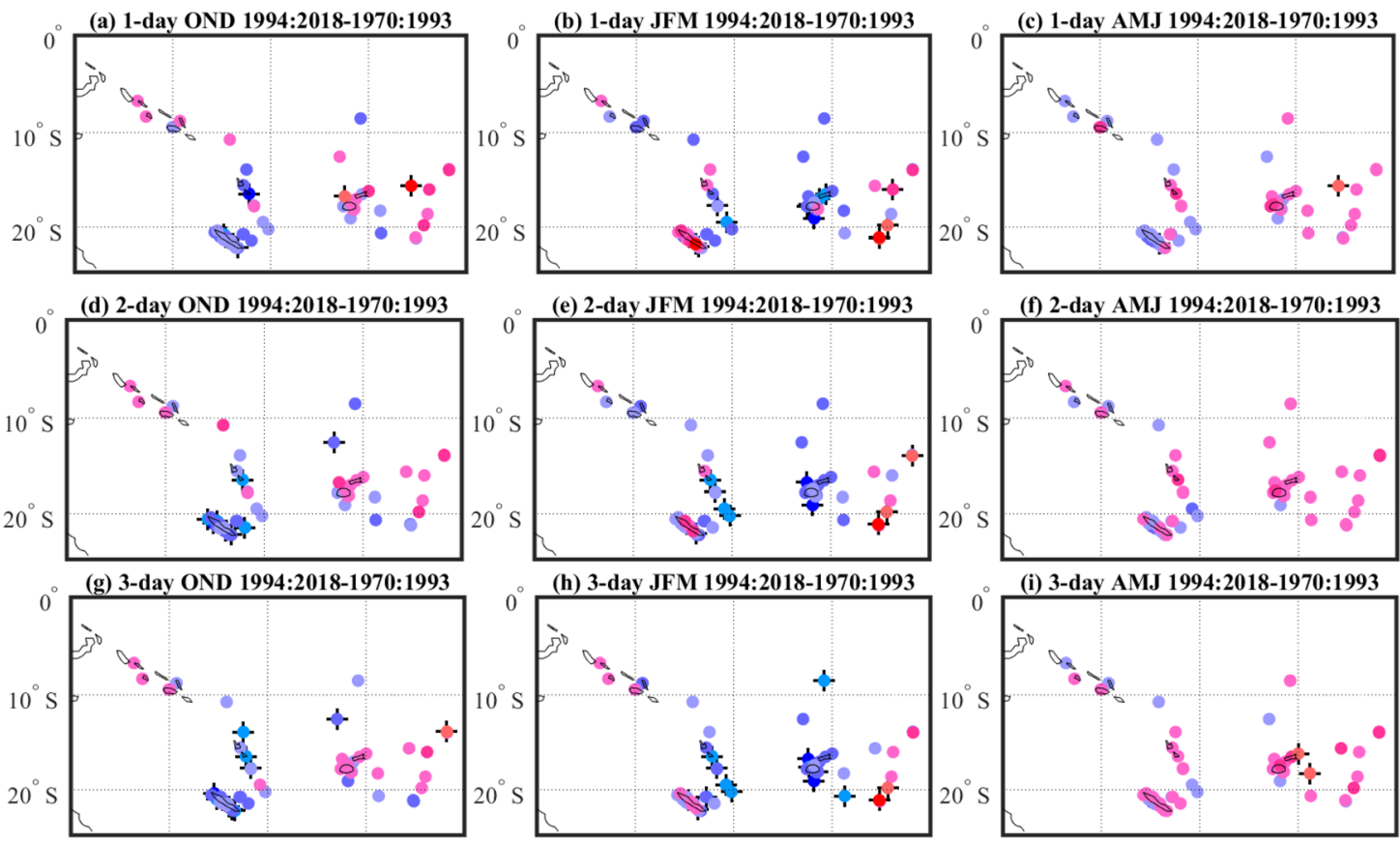

$150^{\circ} \mathrm{E} \quad 160^{\circ} \mathrm{E} \quad 170^{\circ} \mathrm{E} \quad 180^{\circ} \mathrm{E} \quad 190^{\circ} \mathrm{E} \quad 150^{\circ} \mathrm{E} \quad 160^{\circ} \mathrm{E} \quad 170^{\circ} \mathrm{E} \quad 180^{\circ} \mathrm{E} \quad 190^{\circ} \mathrm{E} 150^{\circ} \mathrm{E} \quad 160^{\circ} \mathrm{E} \quad 170^{\circ} \mathrm{E} \quad 180^{\circ} \mathrm{E} \quad 190^{\circ} \mathrm{E}$

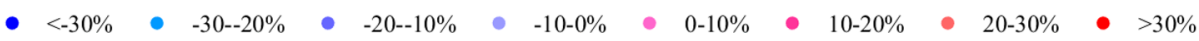

Fig. 7 Maps showing the difference in the contribution of TCs to 1-, 2- and 3-day seasonal maximum daily rainfall between the periods 19942018 and 1970-1993. The crosses denote the percentages that are statistically different from zero at the 5\% confidence level

the 5\% confidence level) over most regions (Fig. 9, black plot). The difference in TC rainfall in a region (considering all stations) over the recent decades has been computed here using seasonal maximum associated with a TC. An examination of the large-scale conditions during the months of November to April show that the average specific and relative humidity at $700-\mathrm{hPa}$, as well as the TC potential intensity (hereafter, PI), have increased during the latter half of the study period compared with the first half in the SWP (Fig. 10). Increasing humidity and PI conditions (Bister and Emanuel 2002; Emanuel 1995) favour intensification of TCs and associated convective activity, leading to increased precipitation. The increase in the number of stronger TCs (Category 3-5) over the SWP region in the recent decades has been confirmed by previous studies (e.g. Tauvale and Tsuboki (2019)). We have extended the analysis to non-TC related extreme rainfall (Fig. 9, red plot), which appears to have also increased over the majority of the Island nations (the difference in non-TC rainfall over the recent decades is computed in a manner similar to that of TCs as discussed above).

The findings here, particularly the increase in the magnitude of TC associated rainfall, are consistent with that reported for the US region (Knight and Davis, 2007). The study by Knight and Davis (2007) shows that extreme precipitation from TCs over the south-eastern US has been increasing over the past few decades. However, in contrast, they report that the contribution of TCs to overall extreme precipitation has been significantly increasing by approximately $5-10 \%$ per decade.

The above findings for the SWP region show that while the frequency of extreme rainfall associated with TCs has decreased in recent decades, the magnitude of such rainfall has increased over the same period. This is consistent with the projected increase in the magnitude of extreme rainfall associated with TCs in a warming climate over the region (e.g. Dutheil et al. 2020 and the references therein) which needs to be taken into consideration in the context of future disaster mitigation and risk assessment.

\subsection{Extreme rainfall probabilities}

The relationship between extreme rainfall events and coexisting modulating factors (such as MJO, ENSO and IPO), including TCs as a source, are often complex in the SWP region (e.g., McGree et al. 2014). A preliminary analysis of selected station rainfall data for the SWP Island countries reveals large variability among TC- and 

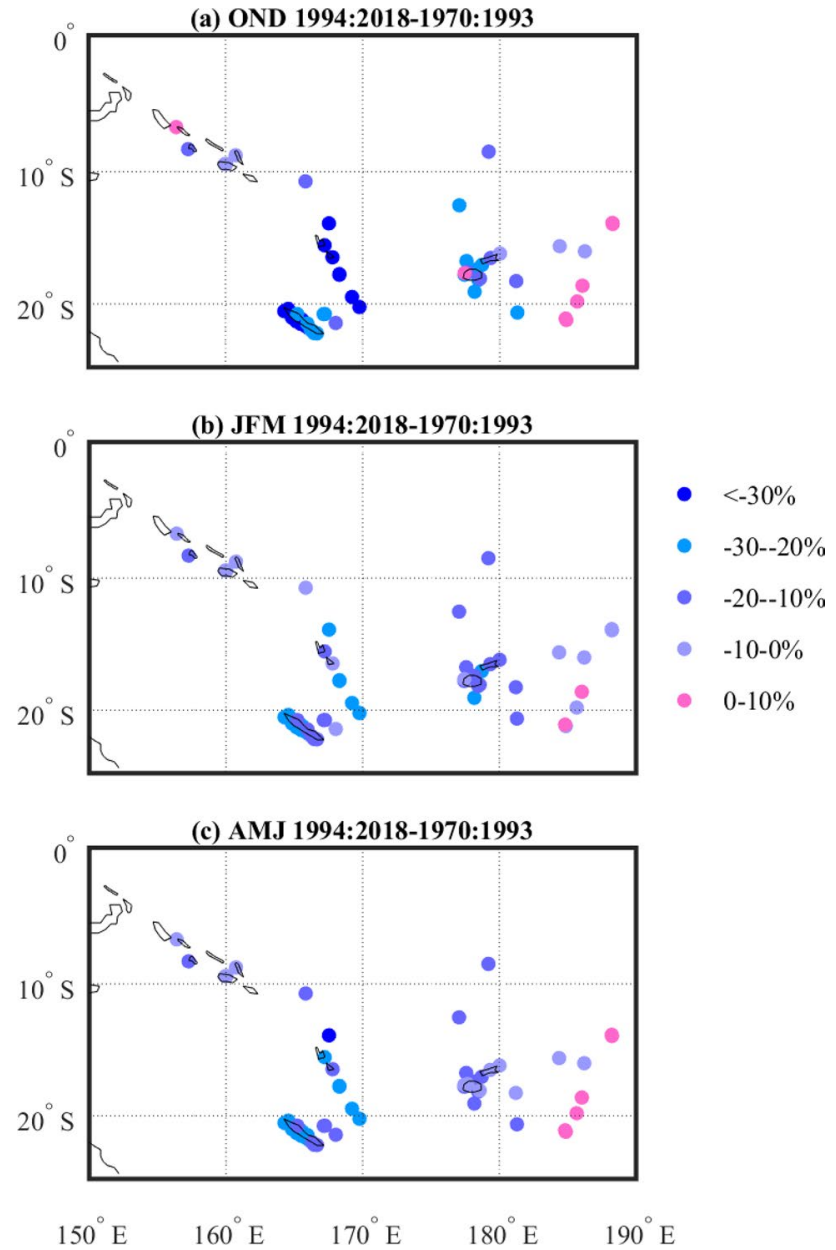

Fig. 8 Maps showing the difference in TC occurrences between the periods 1994-2018 and 1970-1993

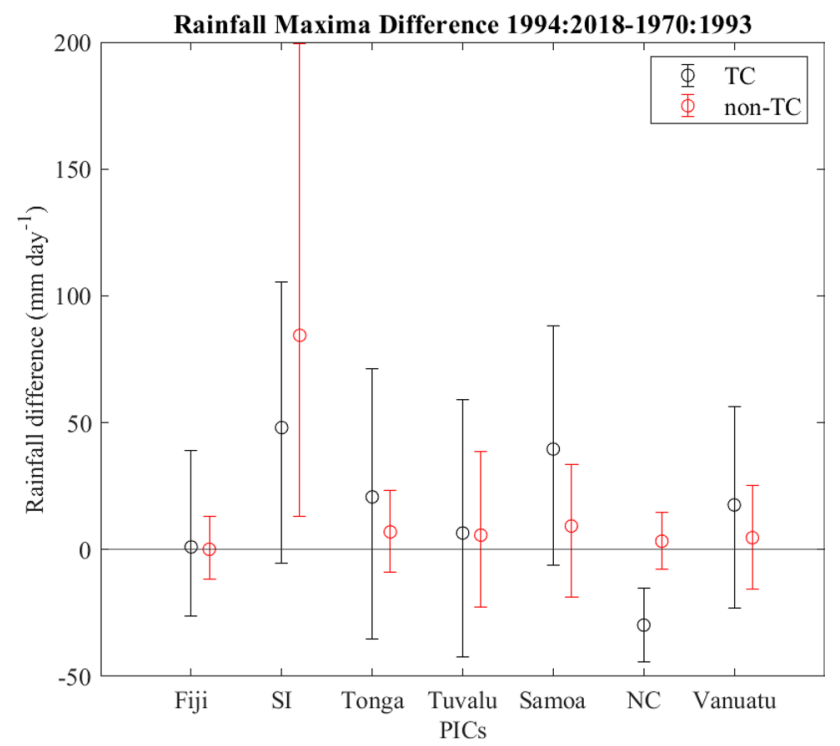

Fig. 9 Difference in mean seasonal maximum daily rainfall associated with TCs and non-TCs between the periods 1994-2018 and 1970-1993
non-TC-related seasonal maximum daily rainfall within each ENSO phase, as well as between different ENSO phases (not shown).

In order to better understand these complex relationships, we developed state-of-the-art probit regression models using Bayesian fitting for selected stations in the SWP Island nations. We examined how the probabilities of the seasonal maximum daily rainfall are likely to have changed if those events were accompanied by different modulating factors. We also examined several cases of recent severe TC events that have caused substantial impacts at local scales in terms of extreme rainfall and flooding. Note here that rainfall activity is considered "high" (denoted " 1 ") if the probability of occurrence of seasonal maximum daily rainfall for a particular season is likely to exceed the median value for the station under consideration (Fig. 11); otherwise the rainfall activity is considered "low" (denoted “0”).

Figure 12 gives the posterior distribution of model parameters associated with different factors that modulate seasonal maximum daily rainfall for selected stations in the SWP (i.e. one station each for Solomon Islands, Vanuatu, New Caledonia, Fiji, Tonga and Samoa). The posterior density distributions on either side of the zero line provide insight into the relative influence of each parameter to the rainfall patterns. For example, a large proportion of the distribution associated with the parameter "TC" lie on the right side of the zero line, indicating that TCs are likely to contribute positively to seasonal maximum daily rainfall probabilities, as expected. However, the extent of contributions by different phases of the MJO, ENSO and IPO appear to vary between stations. For example, the negative phase of ENSO (i.e. La Niña) is likely to increase the probability of seasonal maximum daily rainfall for countries like Samoa and Fiji, as has been noted in some previous studies (e.g., McGree et al. 2014). Similarly, the active phases of the MJO are likely to play a key role in affecting rainfall probabilities for stations like Samoa and Vanuatu. It is beyond the scope of the present study to investigate the physical mechanisms responsible for the different degree of modulations observed for each station. Instead, we emphasise how combinations of these modulating factors are likely to influence the probabilities of seasonal maximum daily rainfall for stations under consideration (Table 2 and Figs. 13, 14, $15,16,17,18)$.

As expected, the probability of seasonal maximum daily rainfall activity exceeding the median value is enhanced substantially in the presence of a TC (as opposed to when a non-TC is present) for all stations under consideration, provided all other conditions remained constant. Over Samoa, for example, the probability of rainfall exceeding the median is higher when a TC is present during the time of an El Niño and an active phase of the MJO (Fig. 13a), as opposed to the 
Fig. 10 Maps showing difference in a relative humidity at $700 \mathrm{hPa}, \mathbf{b}$ specific humidity at $700 \mathrm{hPa}$ and $\mathbf{c}$ potential intensity at $700 \mathrm{hPa}(\mathrm{PI})$ using the National Centre for Environmental Prediction (NCEP) Reanalysis data (Kalnay et al. 1996) for November to April between the periods 1994-2018 and 1970-1993. Box encloses the SWP region

\section{(a) Relative humidty}

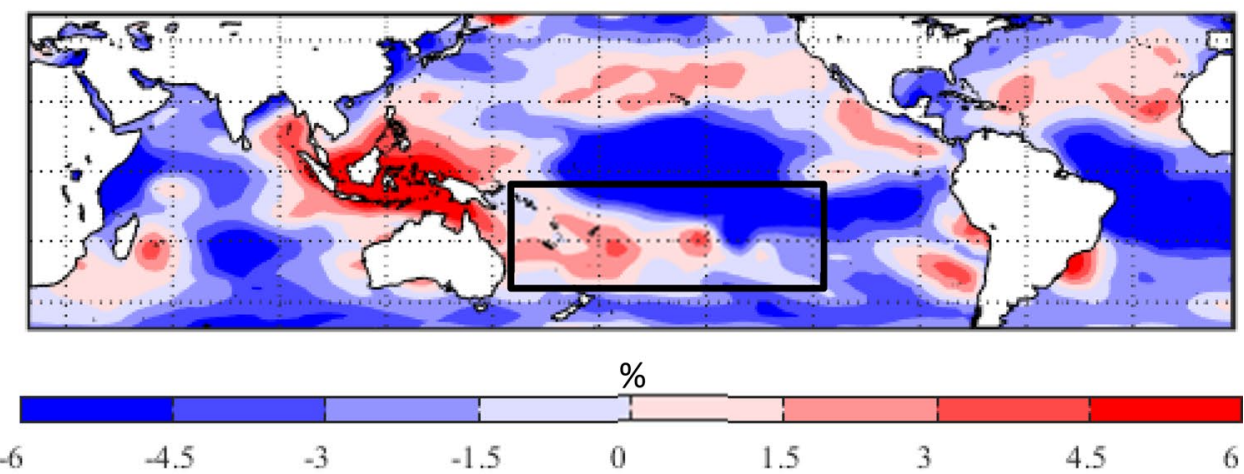

\section{(b) Specific humidty}
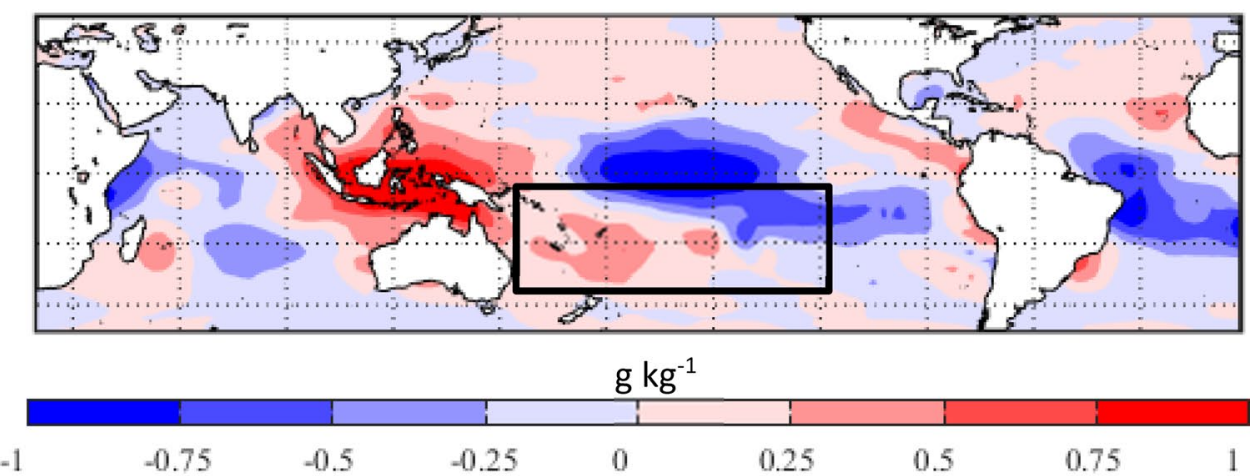

(c) Potential Intensity

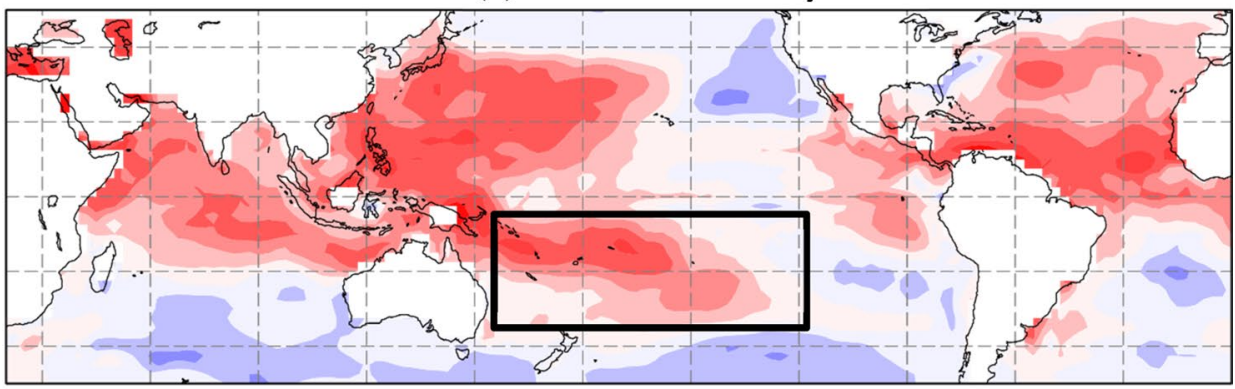

$\mathrm{m} / \mathrm{s}$

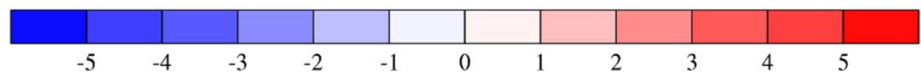

time when a non-TC event is present for the same underlying drivers (Fig. 13b). Similarly, the probability of rainfall exceeding the median is higher when a TC is present during the time of a La Niña and an inactive phase of the MJO phase (Fig. 13g), as opposed to the time when a non-TC event is present for the same underlying drivers (Fig. 13h). All other stations under consideration for different countries show similar results (compare corresponding figures in Figs. 14, 15, 16, 17, 18).
However, the degree of enhancement of the probability of rainfall for TC and non-TC events can be largely controlled by prevailing background conditions at the time, primarily the ENSO and MJO. For example, the probabilities associated with the "high rainfall activity" for Samoa, Fiji and Solomon Island stations are greater when a TC is present during La Niña compared with when one is present during El Niño (Samoa: Fig. 13a vs c and Fig. 13e vs g; Fiji: Fig. 14a vs c and Fig. 14e vs g; Solomon Islands: Fig. 15a vs 


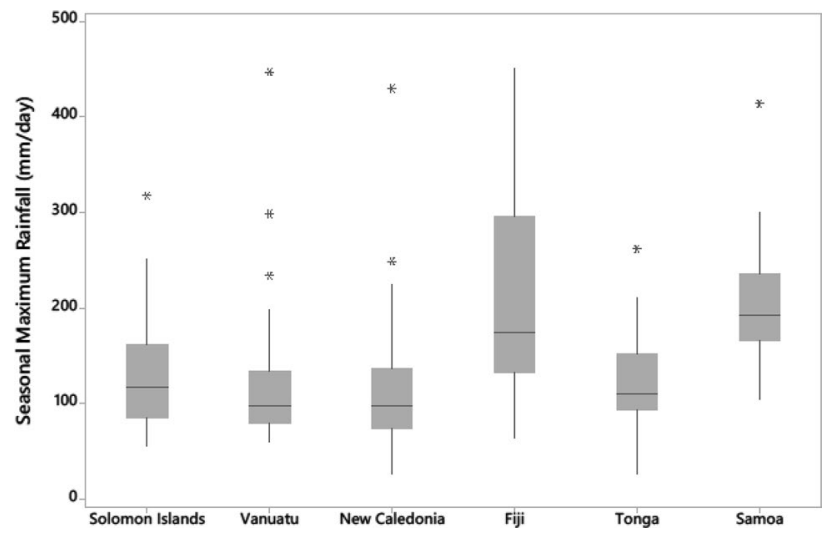

Fig. 11 Boxplot of seasonal maximum rainfall at selected stations. The grey area (box) shows the middle (50th percentile), 75th percentile (top edge i.e. the upper quartile) and the 25 th percentile (lower edge i.e. the lower quartile) values; the whiskers (vertical bars) show the values $\pm 1.5 \times$ interquartile range about the upper and the lower quartiles and the asterisks are the outliers

$\mathrm{c}$ and Fig. 15e vs g). The inverse is true for the southernmost Island nations like Tonga (Fig. 17a vs c and Fig. 17e vs g) and New Caledonia (Fig. 18a vs c and Fig. 18e vs g) where the probabilities associated with "high rainfall activity" are greater when a TC is present during El Niño compared with when one is present during La Niña. The similar patterns of rainfall probability enhancement (and suppression) hold for non-TC events as well for each station. In addition, the ENSO appears to be the primary driver over all the regions in comparison to the $\mathrm{MJO}$ where the latter has greater influence only over Samoa and the Solomon Islands (see Table 3 which summarises the above findings on rainfall probabilities).

For completeness, we have also examined the probabilities of occurrence of extreme rainfall activity associated with cases of recent severe TC events that have caused substantial impacts in different Island nations (Fig. 19). Overall, our models simulated very high probabilities of extreme rainfall for those TCs, which is consistent with observations. For example, in excess of $400 \mathrm{~mm}$ rainfall associated with severe TC Evan was recorded at one of the stations in Samoa. This event caused one of the worst flood-related disasters for Samoa. The model simulated $\sim 70 \%$ probability of rainfall exceeding the median for this event. Similarly, TC Ita caused devastating impacts over the Solomon Islands in terms of flash flooding and extensive damage and losses to property and livelihoods. The model predicted over $65 \%$ chance of rainfall exceeding the median; the rainfall recorded at a station in Solomon Islands was in excess of $300 \mathrm{~mm}$ in $24 \mathrm{~h}$. As such, we see the application of these models for evaluating the exceedance probability of TC, and even non-TC, rainfall events if underlying climatic drivers are known. Such knowledge can be very useful for decision-making and disaster risk reduction.

\section{Summary}

In this study, we have examined the fractional contributions of tropical cyclones (TCs) to extreme rainfall over southwest Pacific Island nations, namely Samoa, Fiji, Solomon Islands, Vanuatu, Tonga and New Caledonia. Data from a total of 52 homogenised daily rainfall stations for the period 1970-2018, provided by the respective national meteorological and hydrological services, have been utilised to compute the fractional contributions of TC-induced extreme rainfall using block maxima and the peak-over-threshold techniques. We show that TCs make significant contributions to extreme rainfall over most of the tropical southwest Pacific Island nations, with the most susceptible regions being New Caledonia, Fiji, Vanuatu and the southern part of the Solomon Islands. Moreover, TC contribution to extreme rainfall generally increases when focus is shifted from single (1-day) to multi-day (2- and 3-day) rainfall accumulation periods. Seasonally, these contributions peak during the months January-February-March (JFM) which can be attributed to the peak TC activity occurring during the latter austral summer period. This peak is also well reflected in the monthly frequency of major floods as presented by McAneney et al (2017) for Fiji.

We have also examined the influence of the MJO on TCinduced extreme rainfall by stratifying the contributions into the active and inactive phases of the MJO. It is apparent from the analyses that TC contributions to seasonal 1-, 2- and 3-day rainfall maximum differ significantly during the different phases of the MJO, with the contributions also varying regionally. The contributions tend to be significantly larger during the active phases of the MJO. The lower contributions of TCs to extreme rainfall are observed during inactive and weak phases of the MJO. It is evident that there are more TC occurrences during the active phase of the MJO than during the inactive and weak phases, consistent with previous studies (Chand and Walsh 2010; Klotzbach 2014). Therefore, it is highly likely that the relatively larger contribution of TCs to extreme rainfall during the active phase of the MJO, as opposed to during the inactive phase, could be primarily due to the larger number of TC occurrences during the active phase.

The relationship between ENSO and TC-induced extreme rainfall is also examined. We found that during La Niña years, TC contributions are larger $(>50 \%)$ over regions west of $170^{\circ} \mathrm{E}$, and lower $(<40 \%)$ for regions east 
(a) Solomon Islands
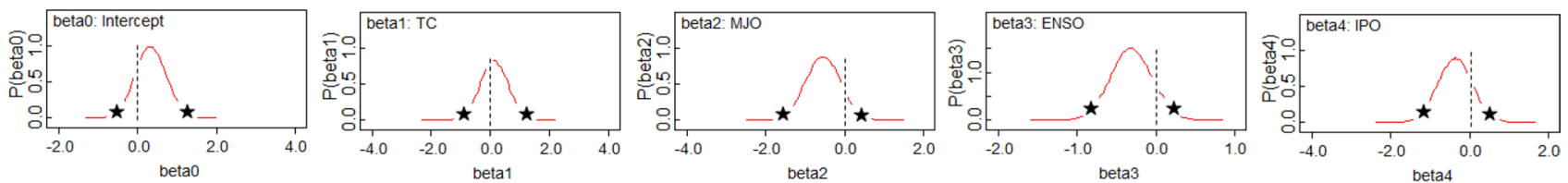

(b) Vanuatu
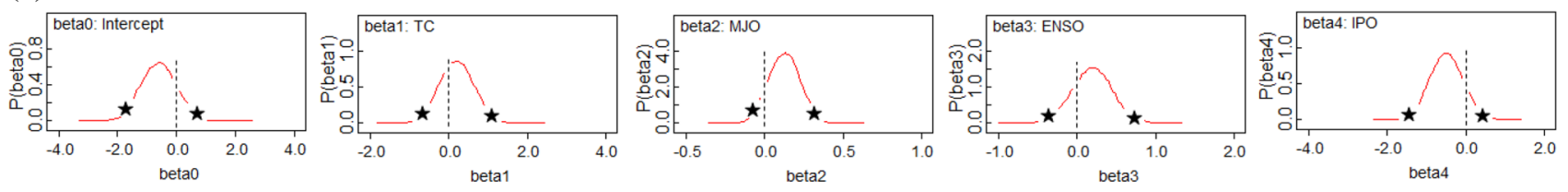

(c) New Caledonia
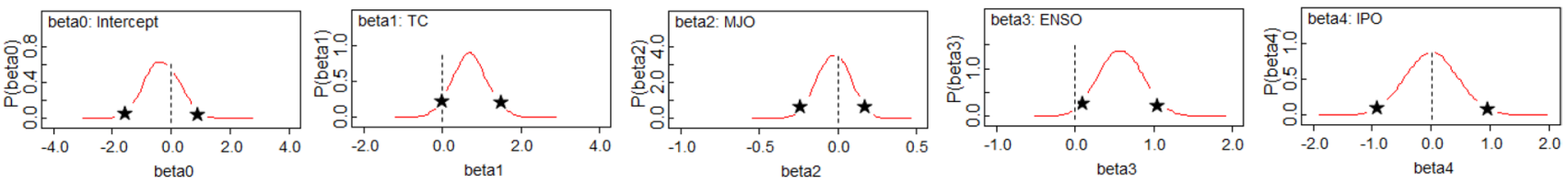

(d) Fiji
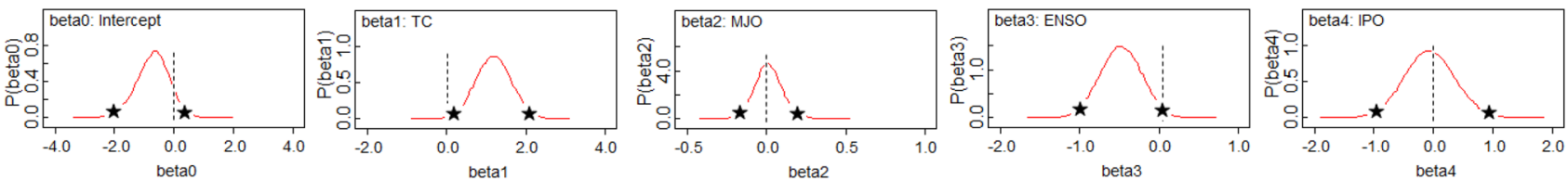

(e) Tonga
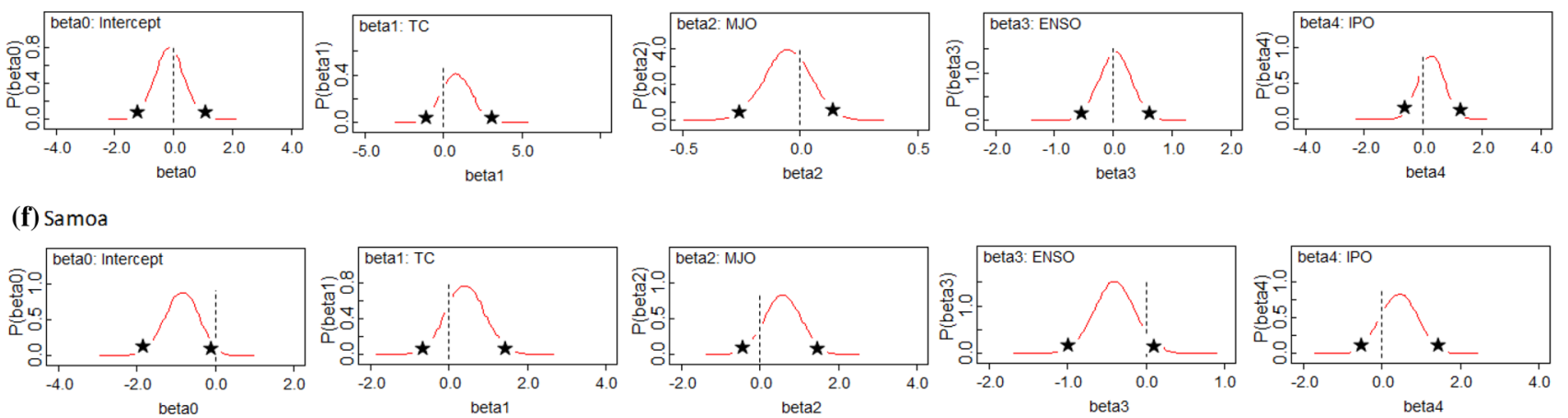

Fig. 12 Posterior density plots of Bayesian regression parameters (rows) for selected stations over each SWP Island nation. The dashed line is the zero reference and the asterisks indicate the $95 \%$ credible interval. 'Beta' refers to the posterior distribution associated with different model parameters, intercept (column 1), TC (column 2), and so on of $170^{\circ} \mathrm{E}$. During ENSO neutral years, TC contributions somewhat decrease for regions equatorward of $15^{\circ} \mathrm{S}$, but increase for regions poleward of $15^{\circ} \mathrm{S}$ and between $160^{\circ} \mathrm{E}$ and $180^{\circ} \mathrm{E}$ (i.e. over New Caledonia and Fiji where contributions are $>60 \%$ ). During El Niño years, TC contributions increase over regions east of $170^{\circ} \mathrm{E}$. In essence, larger contributions (i.e. $>50 \%$ ) systematically shift towards the eastern portion of the southwest Pacific during El Niño years. These changes are consistent with the increased TC activity in the region east of $170^{\circ} \mathrm{E}$ during El Niño as opposed to La Niña years.

This study also investigated whether TC-induced extreme rainfall has varied over recent decades. Our results show that there is a slight decrease in TC contribution to extreme rainfall during the period 1994-2018 when compared with that during the period 1970-1993, particularly over the central southwest Pacific regions and during JFM (statistically significant at the 5\% confidence level over some stations). A contributing factor to this decrease could be an overall decrease in TC incidences over this region. We further showed that the intensity of extreme rainfall associated with individual TCs may have increased over recent decades for most Island nations, consistent with the increase in thermodynamic environmental conditions such as humidity and TC potential intensity (PI) that control TC intensity and associated precipitation. 
Table 2 Probability of occurrence of strong (above the median value) extreme rainfall events for different combination of modulating factors: El Nino and La Nina phases of ENSO (columns), active and inactive phases of the MJO (rows), and TC and non-TC events (bracket separated probability values-values outside the brackets are those associated with TCs and those inside with non-TCs)

\begin{tabular}{llll}
\hline Region & MJO phases & \multicolumn{2}{l}{ TC (non-TC) $\%$} \\
\cline { 3 - 4 } & & El Nino & La Nina \\
\hline Samoa & MJO active & $71(40)$ & $96(90)$ \\
& MJO inactive & $31(3)$ & $76(52)$ \\
Fiji & MJO active & $54(1)$ & $94(34)$ \\
\multirow{2}{*}{ Solomon Islands } & MJO inactive & $53(2)$ & $93(34)$ \\
& MJO active & $15(4)$ & $48(37)$ \\
Vanuatu & MJO inactive & $43(28)$ & $82(76)$ \\
& MJO active & $22(10)$ & $6(2)$ \\
Tonga & MJO inactive & $18(10)$ & $6(2)$ \\
& MJO active & $83(63)$ & $78(56)$ \\
New Caledonia & MJO inactive & $82(65)$ & $77(58)$ \\
& MJO active & $96(70)$ & $42(8)$ \\
& MJO inactive & $94(68)$ & $44(10)$ \\
\hline
\end{tabular}

IPO is positive in all the scenarios. Plots of probabilities for each region are also shown in Figs. 13, 14, 15, 16, 17, 18 to complement this table
Finally, we developed state-of-the-art probit regression models in the Bayesian framework to evaluate synergistic relationships between extreme rainfall and the combinations of various climatic drivers that modulate them for selected stations in the southwest Pacific. These models have substantial skill in simulating the probabilities of extreme rainfall associated with both TC and non-TC events, particularly in simulating how the probabilities of seasonal maximum daily rainfall (i.e. whether rainfall would exceed the station median value or not) are likely to change if a TC event, for example, occurs in different phases of the MJO, ENSO and IPO. As expected, it is shown that the probability of seasonal maximum daily rainfall activity exceeding the median value is enhanced substantially in the presence of a TC for all stations under consideration, provided all other conditions remained constant. However, the degree of enhancement of the probability of rainfall for TC and non-TC events are largely controlled by prevailing background conditions at the time, primarily the ENSO and MJO. For the northernmost Island nations like Samoa, Fiji and the Solomon Islands, the probabilities associated with the "high rainfall activity" are greater when a TC is present during La Niña compared with when one is present during El Niño. The inverse is true for (a)

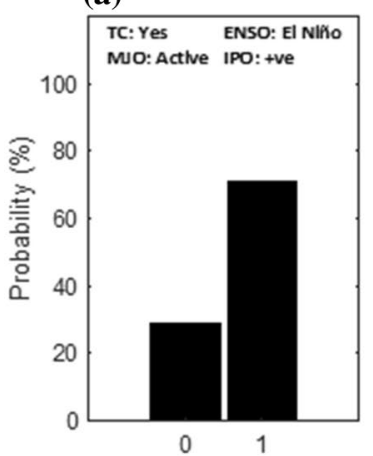

(e)

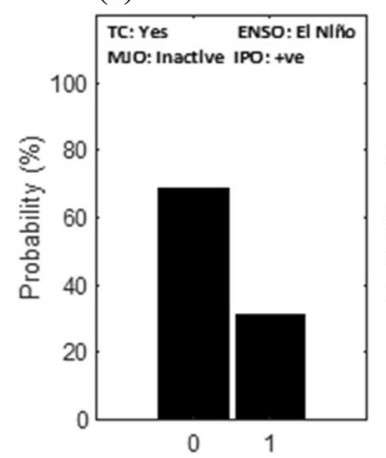

(b)

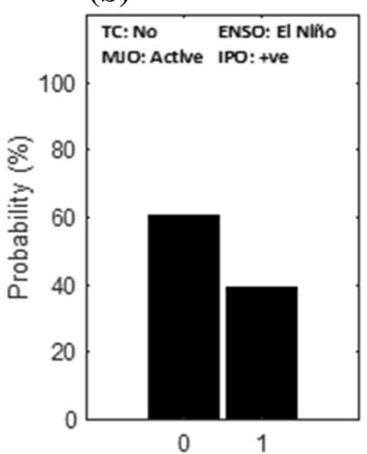

\section{(f)}

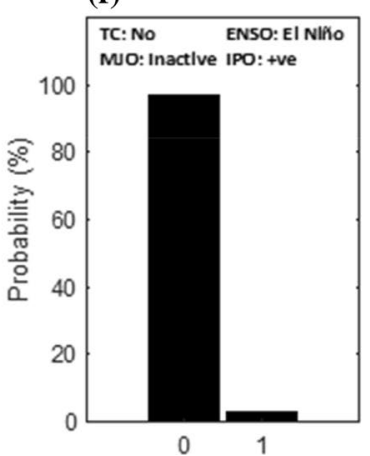

Fig. 13 Probability of occurrence of extreme rainfall events associated with different combinations of modulating factors (rows) for a selected station over Samoa. Binary labels "0" and "1" indicate below

\section{(c)}

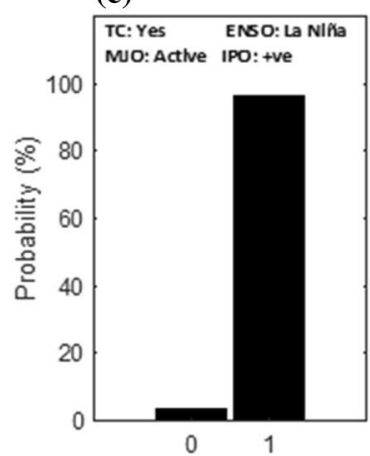

\section{(g)}

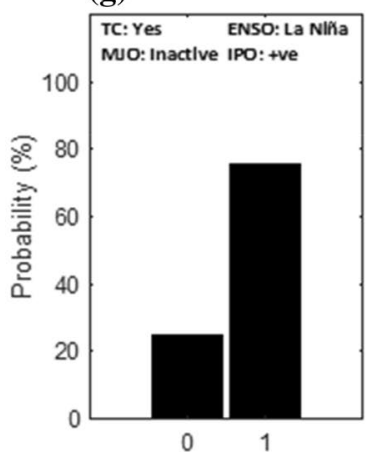

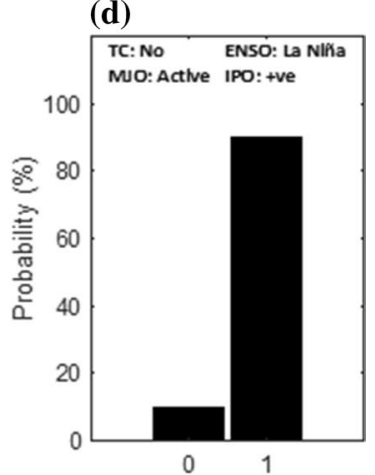

(h)

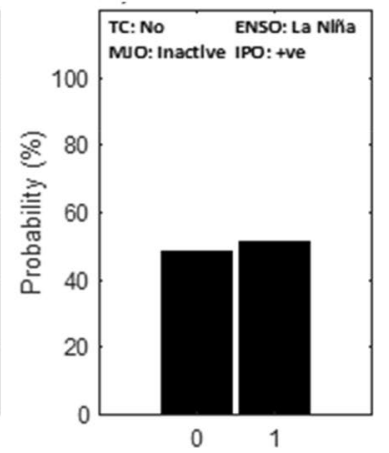

and above median seasonal maximum daily rainfall respectively. See Table 2 for exact values 

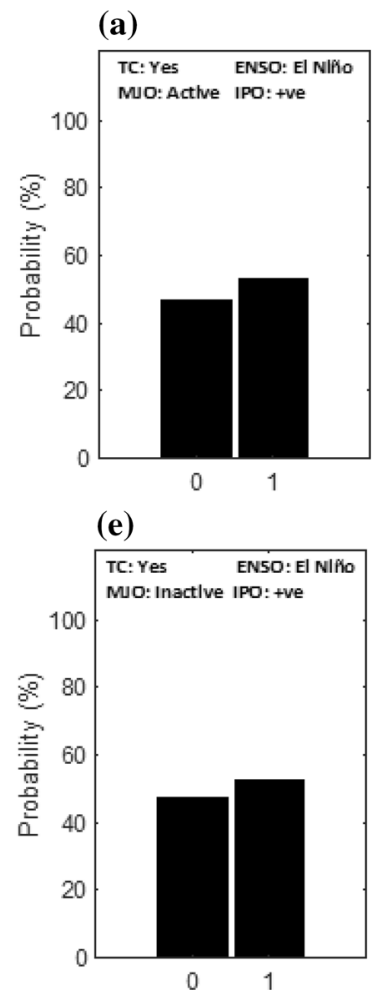

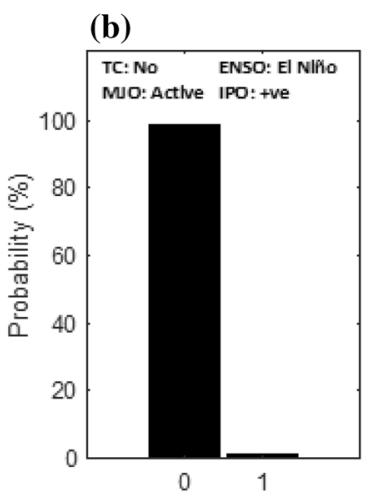

(c)

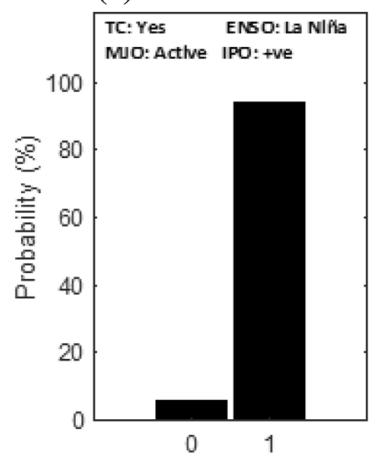

(g)
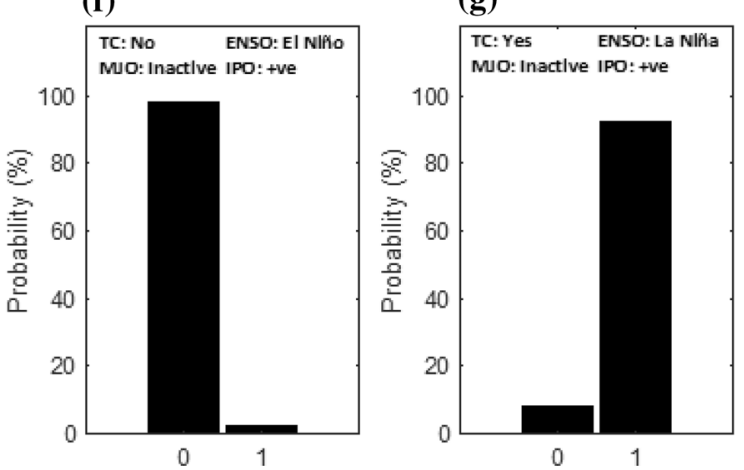

(d)

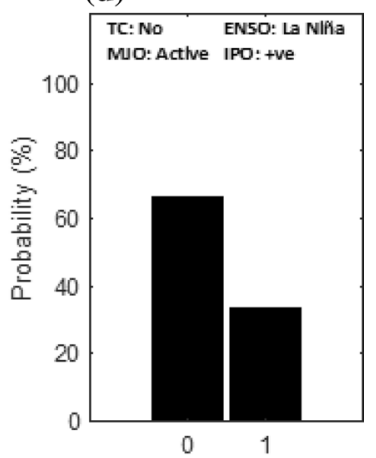

(h)

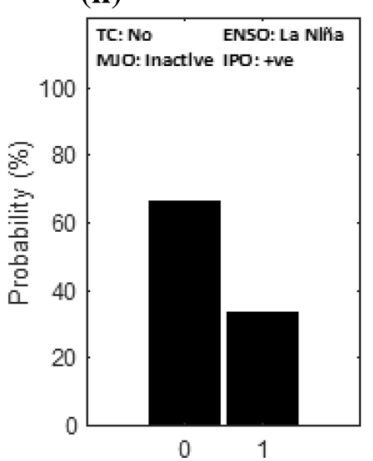

Fig. 14 Same as Fig. 13 but for a station in Fiji

(a)

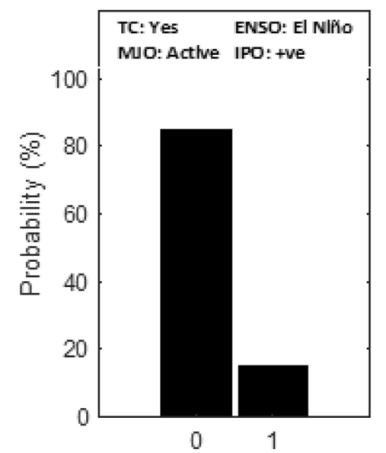

(e)

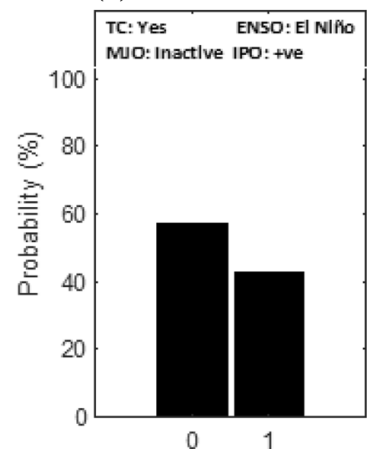

(b)

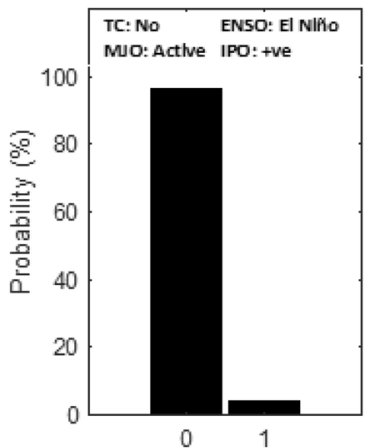

(f)

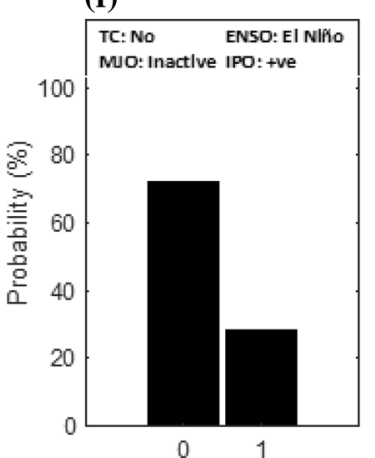

(c)

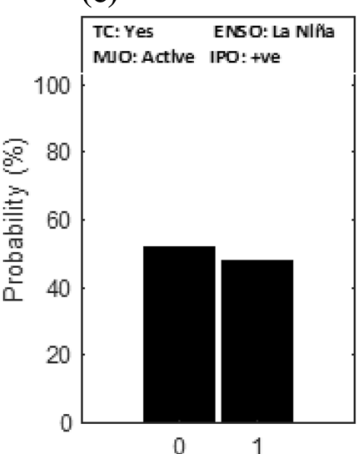

(g)

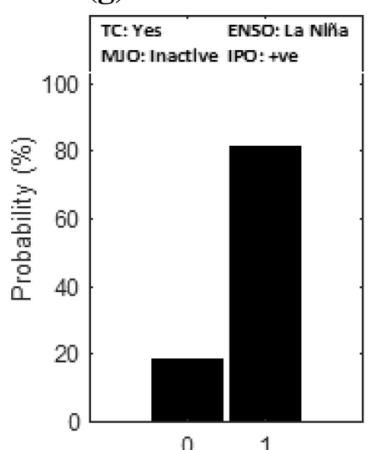

(d)

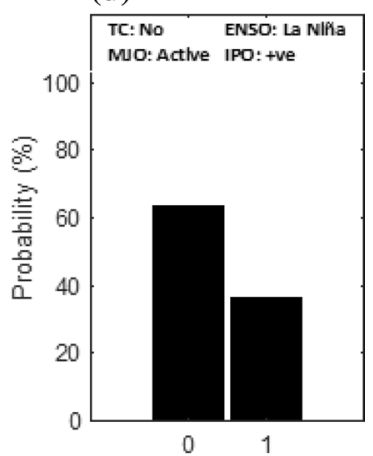

(h)

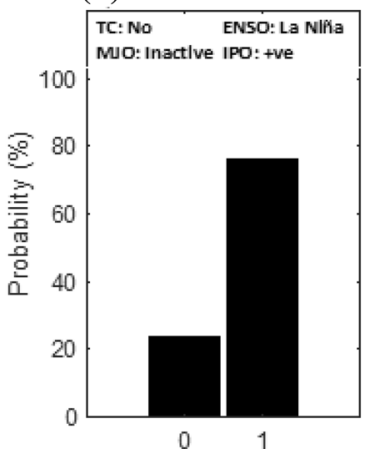

Fig. 15 Same as Fig. 13 but for a station in Solomon Islands 

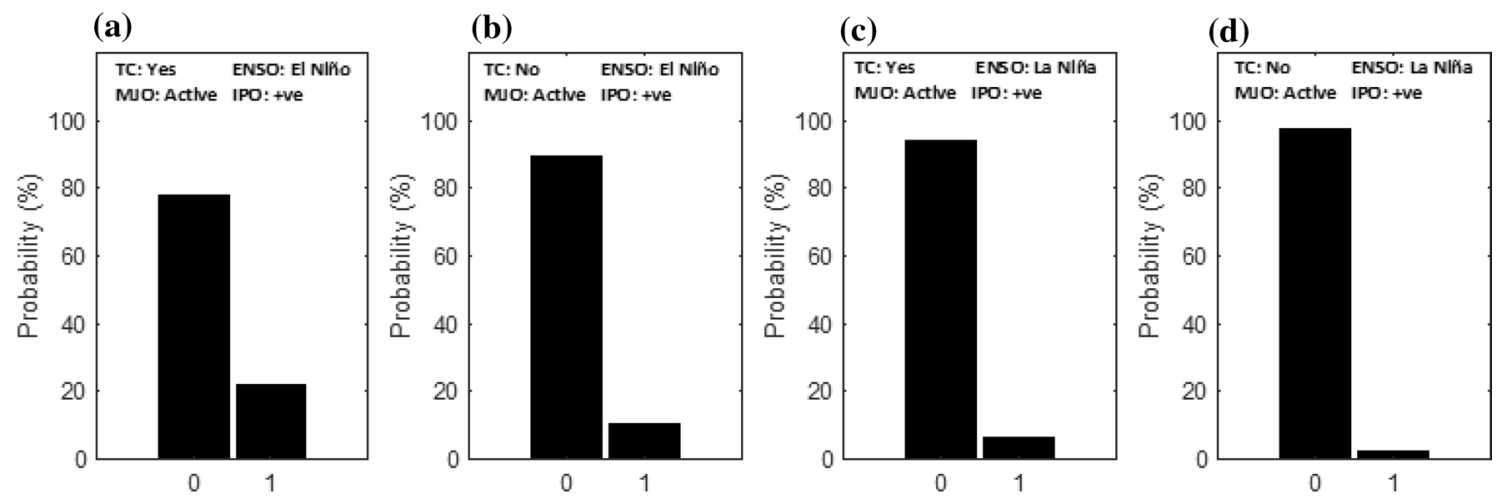

(e)
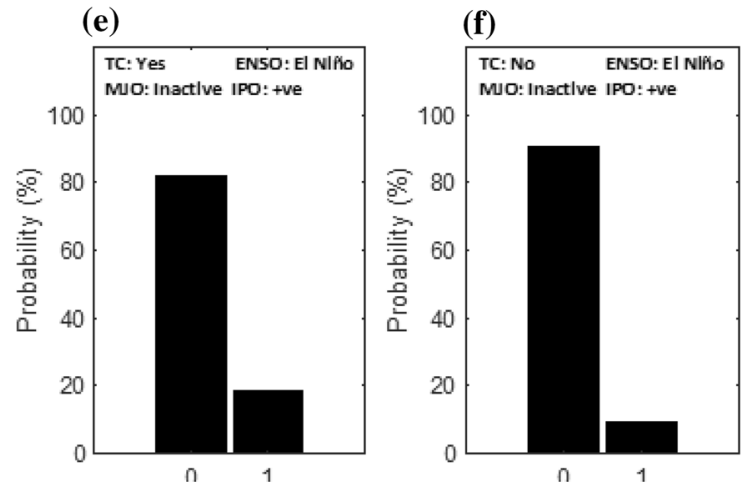

(g)

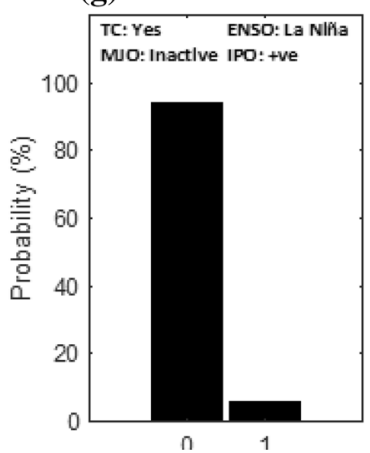

(h)

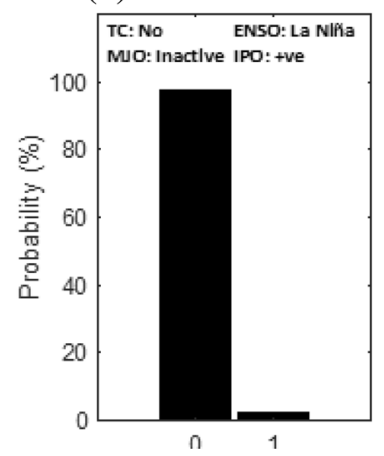

Fig. 16 Same as Fig. 13 but for a station in Vanuatu

(a)

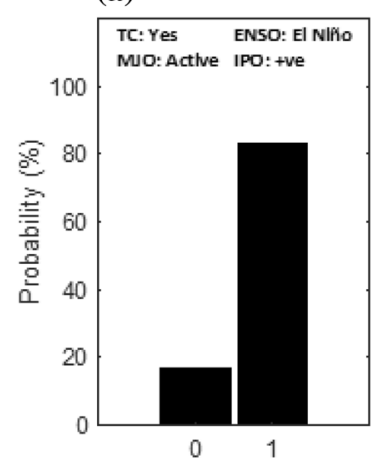

(e)

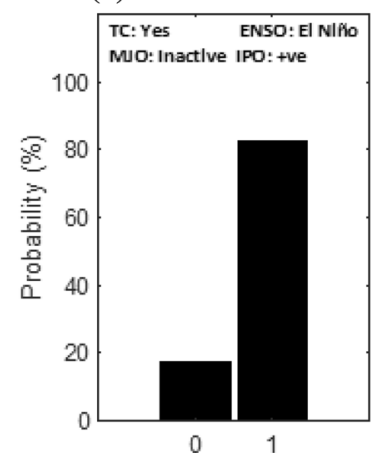

(b)

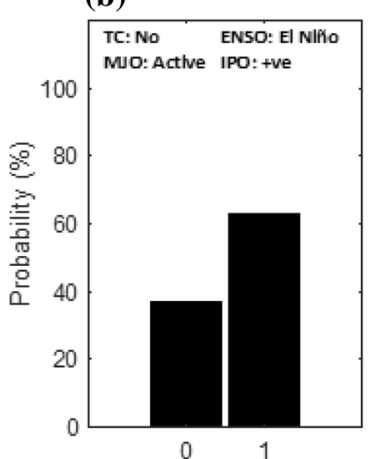

(f)

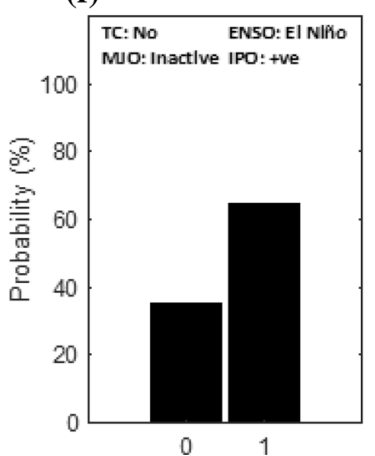

(c)

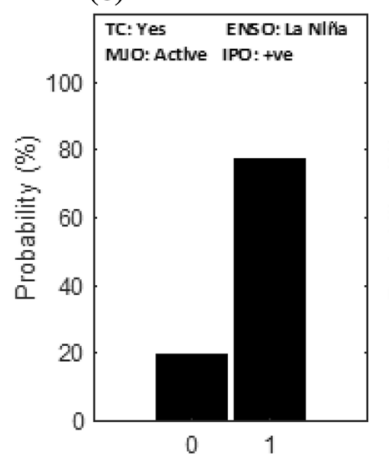

(g)

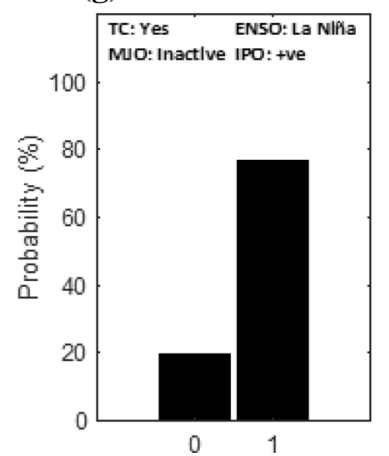

(d)

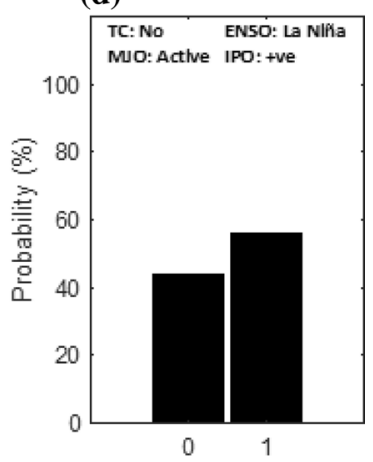

(h)

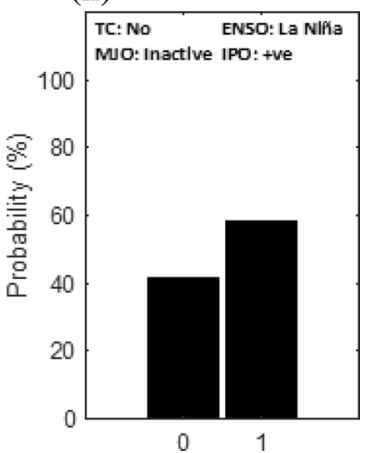

Fig. 17 Same as Fig. 13 but for a station in Tonga 

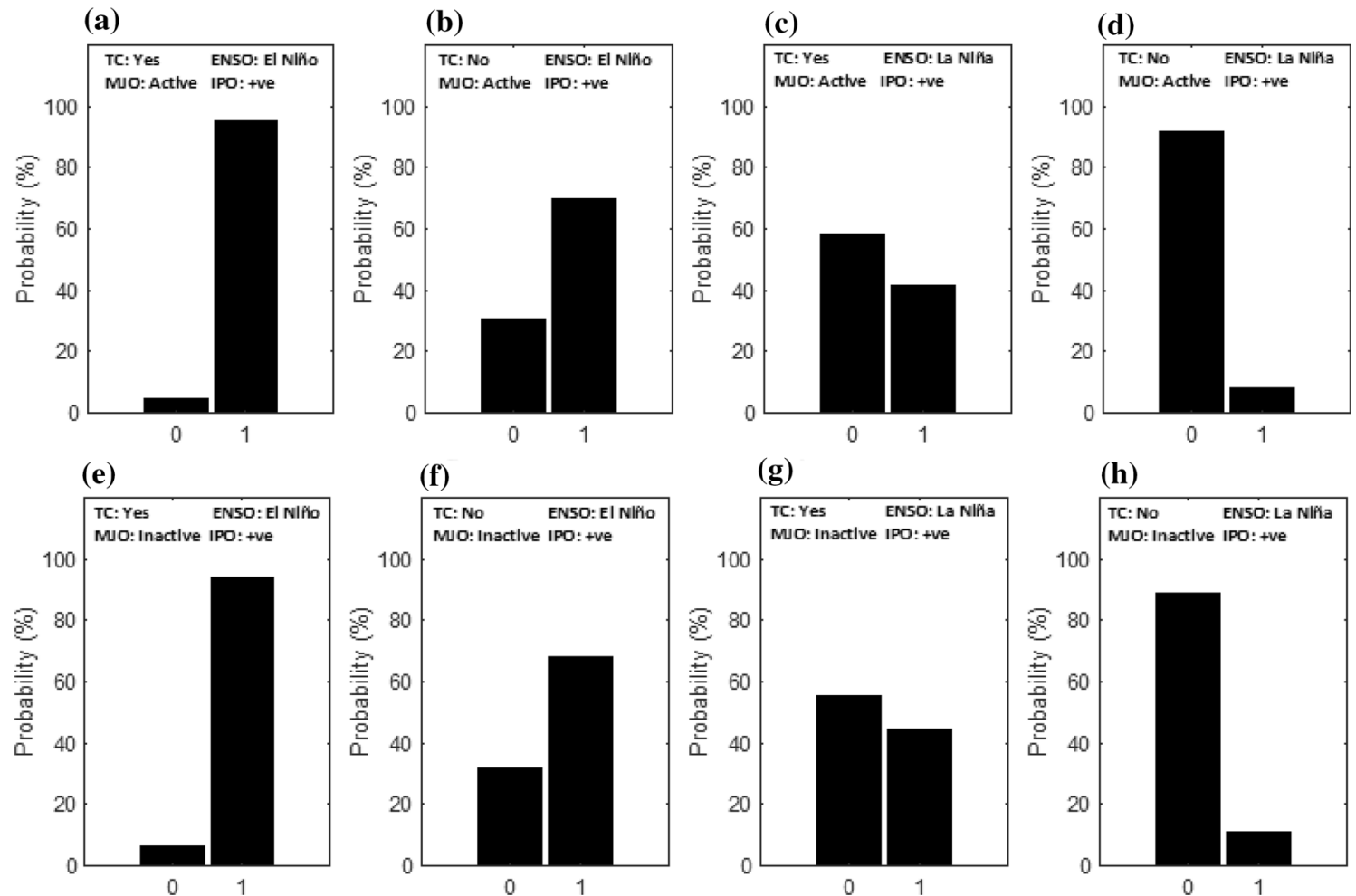

\section{(g)}

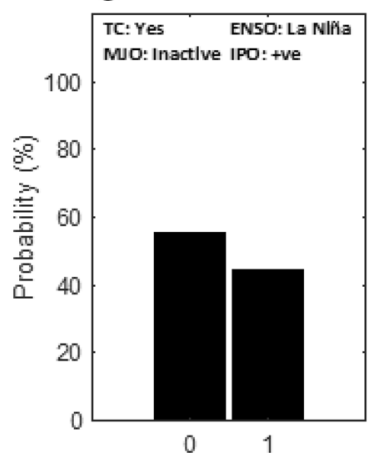

\section{(h)}

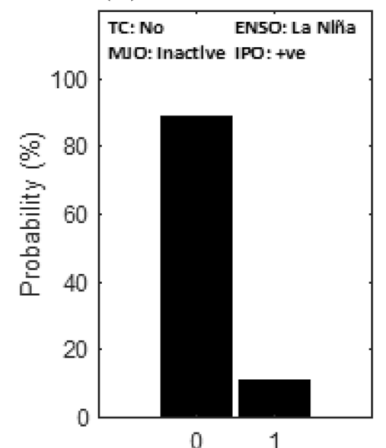

Fig. 18 Same as Fig. 13 but for a station in New Caledonia

Table 3 Combinations of factors for highest and lowest probabilities for strong extreme rainfall for each station from Table 2

\begin{tabular}{|c|c|c|}
\hline Region & Highest probability & Lowest probability \\
\hline Samoa & $96 \%$ - TC/La Nina/MJO active & $3 \%$-Non-TC/El Nino/MJO inactive \\
\hline Fiji & $94 \%$ - TC/La Nina/MJO active & $1 \%$-Non-TC/El Nino/MJO active \\
\hline Solomon Islands & $82 \%$ - TC/La Nina/MJO inactive & $4 \%$-Non-TC/El Nino/MJO active \\
\hline Vanuatu & $22 \%-\mathrm{TC} / \mathrm{El} \mathrm{Nino}$ & $2 \%$-Non-TC/La Nina \\
\hline Tonga & $83 \%$ - TC/El Nino & $56 \%$-Non-TC/La Nina \\
\hline New Caledonia & $96 \%-\mathrm{TC} / \mathrm{El}$ Nino & $8 \%$-Non-TC/La Nina \\
\hline
\end{tabular}

Note, the MJO factor has not been included for Vanuatu, Tonga and New Caledonia since its influence is not evident over these nations-the probability values between the active and inactive phase differ by 4 at most for these nations the southernmost Island nations like Tonga and New Caledonia where the probabilities associated with "high rainfall activity" are greater when a TC is present during El Niño compared with when one is present during La Niña. The similar patterns of rainfall probability enhancement (and suppression) are found for non-TC events as well for each station.
In summary, this study presents new and valuable information about TC-induced extreme rainfall and its association with various modes of climate variability over the southwest Pacific, including the Island nations, on regional to local scales. Results here can have important implications towards development of disaster risk management strategies for the Pacific island nations. 
(a)

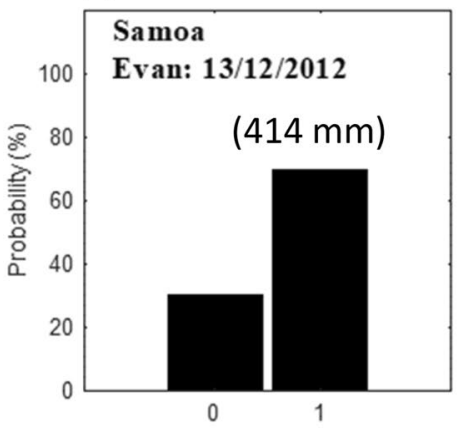

(d)

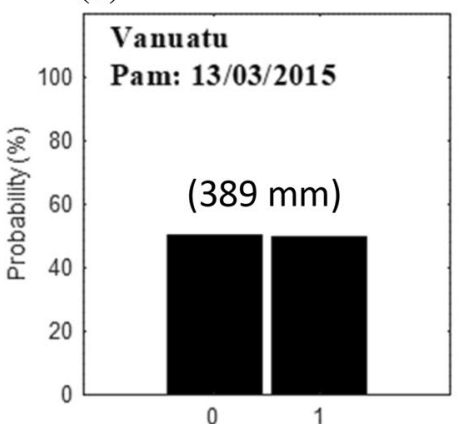

(b)

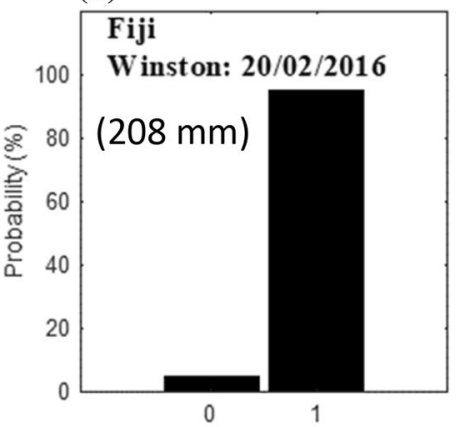

(e)

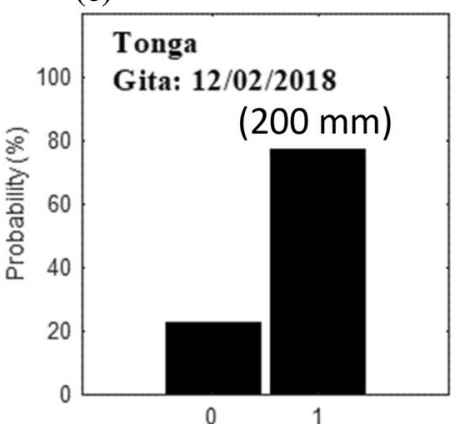

(c)

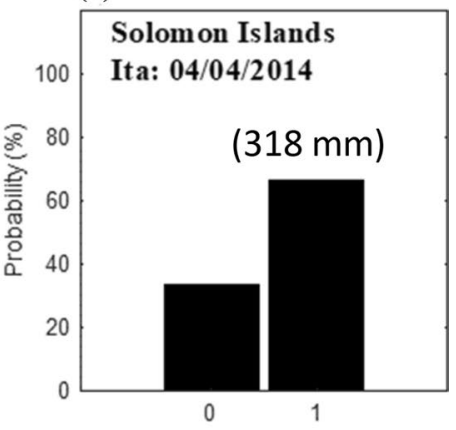

(f)

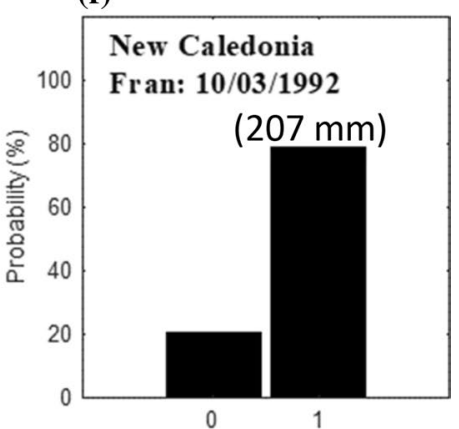

Fig. 19 As per Fig. 13 but for selected severe TC events in the SWP. Numbers in the brackets show the extreme rainfall associated with the selected TCs

\section{Appendix}

\section{A1: Gibbs sampler}

The frequentist approach assumes that values of regression parameters are fixed but unknown and are determined through a maximum likelihood procedure by maximising the likelihood function $f(y \mid \beta)$ for the model. However, the Bayesian approach treats model parameter values not as fixed but as random variables, and inferences concerning the parameters are then obtained by combining the prior belief $f(\boldsymbol{\beta})$ with the most frequent likelihood $f(y \mid \beta)$ using Bayes' rule such that

$f(\beta \mid y) \propto f(\beta) f(y \mid \beta)$.

The posterior distribution $f(\boldsymbol{\beta} \mid \boldsymbol{y})$ is the probability density of $\boldsymbol{\beta}$ conditioned on the observation vector $y$. Prior belief $f(\boldsymbol{\beta})$ refers to information about the values of parameters of interest without reference to the data. In our case, we use noninformative priors of mean of 0 and a variance of $10^{6}$. This very large variance indicates very small precision (i.e., $10^{-6}$ ) and thus contributes little information about the data.

In practice, evaluating analytical solutions of Bayes' equation is computationally difficult. Therefore, the Markov chain Monte Carlo (MCMC) simulation is often considered a desirable alternative to obtain the posterior distribution. A widely used MCMC simulation method is the Gibbs sampler. The Gibbs sampler involves an iterative procedure that generates samples from the posterior distribution by successively using updates from previous samples on the current conditional. Suppose, for example, there are $k$ components of the model parameter vector $\boldsymbol{\beta}$, defined as $\boldsymbol{\beta}=\left[\beta_{1}, \beta_{2}, \ldots\right.$, $\beta_{k}$ ] and $f(\beta \mid y)$ be its posterior distribution given the data $y$. The Gibbs sampling (Gelfand and Smith 1990) then proceeds as follows:

1. Select an arbitrary starting point $\boldsymbol{\beta}^{[0]}=\left[\beta_{1}{ }^{[0]}, \beta_{2}{ }^{[0]}, \ldots\right.$, $\left.\beta_{k}{ }^{[0]}\right]$ and set $i=0$.

2. Generate $\boldsymbol{\beta}^{[i+1]}=\left[\beta_{1}{ }^{[i+1]}, \beta_{2}{ }^{[i+1]}, \ldots, \beta_{k}{ }^{[i+1]}\right]$ as follows:

$$
\begin{aligned}
& \beta_{1}^{[i+1]} \sim f\left(\beta_{1} \mid \beta_{2}^{[i]}, \ldots, \beta_{k}^{[i]}, y\right), \\
& \beta_{2}^{[i+1]} \sim f\left(\beta_{2} \mid \beta_{1}^{[i+1]}, \beta_{3}^{[i]}, \ldots, \beta_{k}^{[i]}, y\right), \\
& \vdots \\
& \beta_{k}^{[1]} \sim f\left(\beta_{k} \mid \beta_{1}^{[i+1]}, \ldots, \beta_{k-1}^{[i+1]}, y\right) .
\end{aligned}
$$

3. Set $i=i+1$ and repeat step 2 until meeting the required number of iterations. 


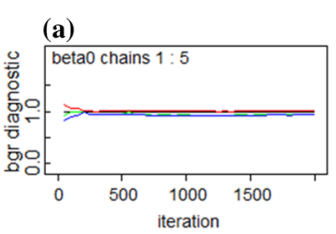

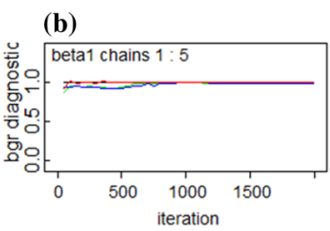

(c)
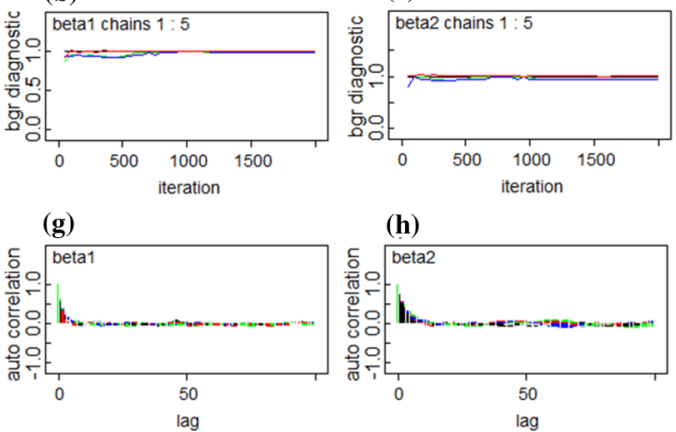

(d)

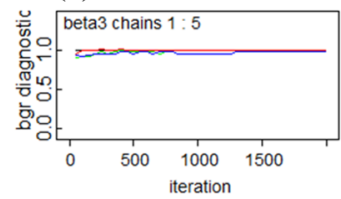

(i)

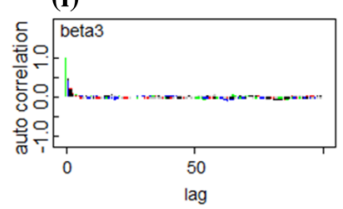

(e)
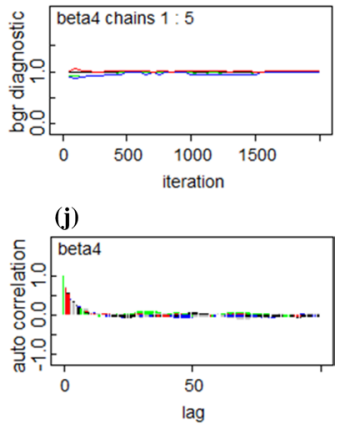

Fig. 20 An example for Samoa station showing (i) five chains for each model parameter where over 2000 iterations are utilised to check model convergence (a-e), and (ii) autocorrelations for each model parameter associated with 2000 iterations to check stationarity assumption (f-j)

Table 4 Schematic of the $2 \times 2$ contingency table

\begin{tabular}{lll}
\hline Modelled & Observed & \\
\cline { 2 - 3 } & Yes & No \\
\hline Yes & Hit $(\mathrm{H})$ & False alarm $(\mathrm{F})$ \\
No & Miss $(\mathrm{M})$ & Correct rejection $(\mathrm{Z})$ \\
\hline
\end{tabular}

In this way, each component of $\boldsymbol{\beta}$ is visited sequentially and the posterior probability distribution of $\boldsymbol{\beta}$ conditioned on the data $y$ (i.e., $f(\boldsymbol{\beta} \mid y)$ ) is obtained. The sampling is implemented for a number of iterations until the output is stable. In our case, we sampled for the total of 7000 iterations, and discard the first 2000 as a "burn-in".

\section{A.2: Model convergence and stationarity}

Establishing convergence with the Gibbs sampler is a crucial step in Bayesian inferences in order to avoid introducing artificial skill in forecasts. Multiple chains are often utilised to check convergence criteria. In our case, we run five chains in parallel. After 2000 iterations, all chains appear to reach a similar steady state indicating model convergence (e.g., see Fig. 20 for the case of Samoa). Moreover, the autocorrelations of each posterior distribution also reach zero fairly quickly (see also Fig. 20 for the case of Samoa). This indicates that stationarity assumptions are satisfied, and so our time series of station rainfall station are free of abrupt and slowly varying changes and periodicities.

\section{A3: Statistical skill scores}

The contingency table (Table 4) is used to determine:
Table 5 Hanssen-Kuipers and bias scores for stations under consideration

\begin{tabular}{lll}
\hline Station & HK score & Bias score \\
\hline Samoa & 0.5 & 1.1 \\
Fiji & 0.5 & 0.8 \\
Solomon Islands & 0.4 & 1.1 \\
Vanuatu & 0.3 & 0.7 \\
Tonga & 0.3 & 0.7 \\
New Caledonia & 0.5 & 1.1 \\
\hline
\end{tabular}

Note that $\mathrm{HK}$ scores range from -1 to +1 , where positive values indicate better skill $(+1$ being perfect). Bias scores that are greater (less) than 1 are indicative of overestimation (underestimation) with the score of 1 representing no biases

1. The Hanssen-Kuipers score (HK), also known as the true skill statistic, following McBride and Ebert (2000) such that

$H K=\frac{H}{M+H}+\frac{Z}{Z+F}-1$,

where the last factor normalises the score between -1 and 1 . This scale is preferred over other measures because it is independent of the distribution of events and non-events and facilitates the comparison of model skill across geographical and seasonal regimes.

2. The bias score, which is a measure of a relative frequency for correctly predicting extreme rain events in our case, is determined as follows

$$
B I A S=\frac{F+H}{M+H}
$$

Results of these scores are summarised in Table 5. Overall, probit models for all basins appear to perform reasonably 
well (HK scores $>0$ for all cases), with noticeably insignificant biases (Bias 1) for most stations.

Acknowledgements This work is supported through the funding from the NextGen 1.5 project, which is an Australian Government's Department of Foreign Affairs and Trade initiative. Prof Neil J. Holbrook is supported by funding from the Australian Research Council Centre of Excellence for Climate Extremes (CE170100023) and the Australian Government National Environmental Science Programme (NSEP) Earth Systems and Climate Change Hub. The authors thank Mr. Nikotemo Iona of Tuvalu Meteorological Services, and Ms. Olivia Yu and Dr. Alexandre Peltier of Météo France, New Caledonia, for providing rainfall data for their respective countries. The authors also thank Prof Suzana Camargo of Lamont-Doherty Earth Observatory (Columbia University) for providing tropical cyclone potential intensity data.

Funding This work is supported through the funding from the NextGen 1.5 project, which is an Australian Government's Department of Foreign Affairs and Trade initiative.

Availability of data and material Available upon request.

\section{Declaration}

\section{Conflict of interest None.}

Code availability Available upon request.

Open Access This article is licensed under a Creative Commons Attribution 4.0 International License, which permits use, sharing, adaptation, distribution and reproduction in any medium or format, as long as you give appropriate credit to the original author(s) and the source, provide a link to the Creative Commons licence, and indicate if changes were made. The images or other third party material in this article are included in the article's Creative Commons licence, unless indicated otherwise in a credit line to the material. If material is not included in the article's Creative Commons licence and your intended use is not permitted by statutory regulation or exceeds the permitted use, you will need to obtain permission directly from the copyright holder. To view a copy of this licence, visit http://creativecommons.org/licenses/by/4.0/.

\section{References}

Adler RF et al (2017) Global Precipitation Climatology Project (GPCP) Climate Data Record (CDR), Version 1.3 (Daily), NOAA National Centers for Environmental Information. https://doi.org/10.7289/ V5RX998Z. Accessed 25 Jan 2021

Albert JH, Chib S (1993) Bayesian analysis of binary and polychotomous response data. J Am Stat Assoc 88:669-679. https://doi. org $/ 10.2307 / 2290350$

Antinao JL, Farfán LM (2013) Occurrence of landslides during the approach of tropical cyclone Juliette (2001) to Baja California Sur, Mexico. J Atmósfera 26:183-208

Aryal YN, Villarini G, Zhang W, Vecchi GA (2019) Long term changes in flooding and heavy rainfall associated with North Atlantic tropical cyclones: Roles of the North Atlantic Oscillation and El NiñoSouthern Oscillation. J Hydrol 559:698-710

Bagtasa G (2017) Contribution of tropical cyclones to rainfall in the Philippines. J Climate 30:3621-3633. https://doi.org/10.1175/ JCLI-D-16-0150.1
Basher RE, Zheng X (1995) Tropical cyclones in the Southwest Pacific: spatial patterns and relationships to southern oscillation and sea surface temperature. J Climate 8:1249-1260. https://doi. org/10.1175/1520-0442(1995)008<1249:TCITSP > 2.0.CO;2

Bister M, Emanuel KA (2002) Low frequency variability of tropical cyclone potential intensity 1 . Interannual to interdecadal variability. J Geophys Res [Atmos] 107:ACL 26-21-ACL 26-15. https:// doi.org/10.1029/2001JD000776

Callaghan J, Power S (2014) Major coastal flooding in southeastern Australia 1860-2012, associated deaths and weather systems. Austral Meteorol Oceanogr J 64:183-214. https://doi. org/10.22499/2.6403.002

Chand SS, Walsh KJE (2009) Tropical cyclone activity in the Fiji region: spatial patterns and relationship to large-scale circulation. J Climate 22:3877-3893. https://doi.org/10.1175/2009JCLI2880.1

Chand SS, Walsh KJE (2010) The influence of the Madden-Julian oscillation on tropical cyclone activity in the Fiji Region. J Climate 23:868-886. https://doi.org/10.1175/2009JCLI3316.1

Chand SS, Walsh KJE (2011a) Forecasting tropical cyclone formation in the Fiji region: a probit regression approach using Bayesian fitting. Weather Forecast 26:150-165. https://doi. org/10.1175/2010WAF2222452.1

Chand SS, Walsh KJE (2011b) Influence of ENSO on tropical cyclone intensity in the Fiji region. J Climate 24:4096-4108. https://doi. org/10.1175/2011JCLI4178.1

Chand SS, Walsh KJE (2012) Modeling seasonal tropical cyclone activity in the Fiji region as a binary classification problem. J Climate 25:5057-5071. https://doi.org/10.1175/JCLI-D-11-00507.1

Chand SS, Tory KJ, McBride JL, Wheeler MC, Dare RA, Walsh KJE (2013) The different impact of positive-neutral and negativeneutral ENSO regimes on Australian tropical cyclones. J Climate 26:8008-8016. https://doi.org/10.1175/JCLI-D-12-00769.1

Chavas DR, Lin N, Dong W, Lin Y (2016) Observed tropical cyclone size revisited. J Climate 29:2923-2939. https://doi.org/10.1175/ JCLI-D-15-0731.1

Chen J-M, Tan P-H, Shih C-F (2013) Heavy rainfall induced by tropical cyclones across northern Taiwan and associated intraseasonal oscillation modulation. J Climate 26:7992-8007. https://doi. org/10.1175/JCLI-D-12-00692.1

Chu P-S, Zhao X, Ruan Y, Grubbs M (2009) Extreme rainfall events in the Hawaiian Islands. J Appl Meteorol Climatol 48:502-516. https://doi.org/10.1175/2008JAMC1829.1

Cogan J, Gratchev I, Wang G (2018) Rainfall-induced shallow landslides caused by ex-Tropical Cyclone Debbie, 31st March 2017. Landslides 15:1215-1221

Coles S (2001) An introduction to statistical modeling of extreme values. Springer, New York, p 97.https://doi.org/10.2307/3085846

Dare RA, Davidson NE, McBride JL (2012) Tropical cyclone contribution to rainfall over Australia. Mon Weather Rev 140:3606-3619. https://doi.org/10.1175/MWR-D-11-00340.1

Diamond HJ, Renwick JA (2015) The climatological relationship between tropical cyclones in the southwest pacific and the Madden-Julian Oscillation. Int J Climatol 35:676-686. https://doi. org/10.1002/joc.4012

Diamond HJ, Lorrey AM, Knapp KR, Levinson DH (2012) Development of an enhanced tropical cyclone tracks database for the southwest Pacific from 1840 to 2010. Int J Climatol 32:22402250. https://doi.org/10.1002/joc. 2412

Diamond HJ, Lorrey AM, Renwick JA (2013) A southwest pacific tropical cyclone climatology and linkages to the El Niño-Southern oscillation. J Climate 26:3-25. https://doi.org/10.1175/ JCLI-D-12-00077.1

Dowdy A, Kuleshov Y (2012) An analysis of tropical cyclone occurrence in the Southern Hemisphere derived from a new satellite-era data set. Int J Remote Sens 33:7382-7397. https://doi. org/10.1080/01431161.2012.685986 
Dutheil C, Lengaigne M, Bador M et al (2020) Impactofprojectedseasurfacetemperaturebiases on tropical cyclones projections in the South Pacific. Sci Rep 10:4838. https://doi.org/10.1038/ s41598-020-61570-6

Efron B, Tibshirani R (1991) Statistical data analysis in the computer age. Science 253:390. https://doi.org/10.1126/scien ce. 253.5018 .390

Elsner JB, Schmertmann CP (1994) Assessing forecast skill through cross validation. Weather Forecast 9:619-624. https://doi. org/10.1175/1520-0434(1994)009<0619:AFSTCV>2.0.CO;2

Elsner JB, Jagger TH, Dickinson M, Rowe D (2008) Improving multiseason forecasts of north Atlantic hurricane activity. J Climate 21:1209-1219. https://doi.org/10.1175/2007JCLI1731.1

Emanuel KA (1995) Sensitivity of tropical cyclones to surface exchange coefficients and a revised steady-state model incorporating eye dynamics. J Atmos Sci 52:3969-3976. https://doi. org/10.1175/1520-0469(1995)052<3969:SOTCTS >2.0.CO;2

Folland CK, Renwick JA, Salinger MJ, Mullan AB (2002) Relative influences of the Interdecadal Pacific Oscillation and ENSO on the South Pacific Convergence Zone. Geophys Res Lett 29:2124. https://doi.org/10.1029/2001GL014201

Gelfand AE, Smith AFM (1990) Sampling-based approaches to calculating marginal densities. J Am Stat Assoc 85:398-409. https ://doi.org/10.2307/2289776

Gelman A, Rubin DB (1992) Inference from iterative simulation using multiple sequences. Stat Sci 7:457-472

Gershunov A, Barnett TP (1998) Interdecadal modulation of ENSO teleconnections. Bull Am Meteorol Soc 79:2715-2726. https:// doi.org/10.1175/1520-0477(1998)079<2715:IMOET>2.0.CO;2

Griffiths GM, Salinger MJ, Leleu I (2003) Trends in extreme daily rainfall across the South Pacific and relationship to the South Pacific Convergence Zone. Int J Climatol 23:847-869. https:// doi.org/10.1002/joc.923

Guo L, Klingaman NP, Vidale PL, Turner AG, Demory M-E, Cobb A (2017) Contribution of tropical cyclones to atmospheric moisture transport and rainfall over East Asia. J Climate 30:38533865. https://doi.org/10.1175/JCLI-D-16-0308.1

Haffke C, Magnusdottir G (2013) The South Pacific Convergence Zone in three decades of satellite images. J Geophys Res Atmos 118:10839-810849. https://doi.org/10.1002/jgrd.50838

Henley BJ, Gergis J, Karoly DJ, Power SB, Kennedy J, Folland CK (2015) A tripole index for the interdecadal Pacific oscillation. Climate Dyn 45:3077-3090

Huffman GJ, Adler RF, Morrissey MM, Bolvin DT, Curtis S, Joyce R, McGavock B, Susskind J (2001) Global precipitation at one-degree daily resolution from multisatellite observations. J Hydrometeorol 2:36-50. https://doi. org/10.1175/1525-7541(2001)002\%3c0036:GPAODD\%3e2.0 $\mathrm{CO} ; 2$

Jiang H, Zipser EJ (2010) Contribution of tropical cyclones to the global precipitation from eight seasons of TRMM data: regional, seasonal, and interannual variations. J Climate 23(6):1526-1543

Jourdain NC, Marchesiello P, Menkes CE, Lefèvre J, Vincent EM, Lengaigne M, Chauvin F (2011) Mesoscale simulation of tropical cyclones in the South Pacific: climatology and interannual variability. J Climate 24:3-25. https://doi.org/10.1175/2010JCLI3559.1

Karoly DJ, Vincent DG (1998) Meteorology of the Southern Hemisphere. Meteorol Monogr 49:1-410. https://doi. org/10.1175/0065-9401-27.49.1

Kalnay E et al (1996) The NCEP/NCAR 40-year reanalysis project. Bull Am Meteorol Soc 77:437-472. https://doi.org/10.1175/15200477(1996)077<0437:TNYRP>2.0.CO;2

Khouakhi A, Villarini G, Vecchi GA (2017) Contribution of tropical cyclones to rainfall at the global scale. J Climate 30:359-372. https://doi.org/10.1175/JCLI-D-16-0298.1
Klotzbach P (2014) The Madden-Julian Oscillation's impacts on worldwide tropical cyclone activity. J Climate 27:2317-2330. https://doi.org/10.1175/JCLI-D-13-00483.1

Knight DB, Davis RE (2007) Climatology of tropical cyclone rainfall in the southeastern United States. Phys Geogr 28:126-147. https ://doi.org/10.2747/0272-3646.28.2.126

Knight DB, Davis RE (2009) Contribution of tropical cyclones to extreme rainfall events in the southeastern United States. J Geophys Res Atmos. https://doi.org/10.1029/2009JD012511

Knutson T et al (2019) Tropical cyclones and climate change assessment: part I. Detection and attribution. BAMS. https://doi. org/10.1175/BAMS-D-18-0189.1

Kuleshov Y, Qi L, Fawcett R, Jones D (2008) On tropical cyclone activity in the Southern Hemisphere: trends and the ENSO connection. Geophys Res Lett. https://doi.org/10.1029/2007GL032983

Kuleshov Y, Fawcett R, Qi L, Trewin B, Jones D, McBride J, Ramsay $H$ (2010) Trends in tropical cyclones in the South Indian Ocean and the South Pacific Ocean. J Geophys Res 115:D01101. https ://doi.org/10.1029/2009JD012372

Landsea CW, Harper BA, Hoarau K, Knaff JA (2006) Can we detect trends in extreme tropical cyclones? Science 313:452-454

Larson J, Zhou Y, Higgins RW (2005) Characteristics of landfalling tropical cyclones in the United States and Mexico: climatology and interannual variability. J Climate 18:1247-1262. https://doi. org/10.1175/JCLI3317.1

Lau KM, Zhou YP, Wu HT (2008) Have tropical cyclones been feeding more extreme rainfall? J Geophys Res Atmos. https://doi. org/10.1029/2008JD009963

Leroy A, Leroy A, Wheeler MC (2008) Statistical prediction of weekly tropical cyclone activity in the Southern Hemisphere. Mon Weather Rev 136(10):3637-3654

Madden RA, Julian PR (1971) Detection of a 40-50 day oscillation in the zonal wind in the tropical Pacific. J Atmos Sci 28:702-708. https://doi.org/10.1175/1520-0469(1971)028\%3c0702:DOADO I\%3e2.0.CO;2

Madden RA, Julian PR (1994) Observations of the 40-50-Day tropical oscillation-a review. Mon Weather Rev 122:814-837. https://doi.org/10.1175/1520-0493(1994)122\%3c0814:OOTDT $\mathrm{O} \% 3 \mathrm{e} 2.0 . \mathrm{CO} ; 2$

Magee AD, Verdon-Kidd DC, Diamond HJ, Kiem AS (2017) Influence of ENSO ENSO Modoki, and the IPO on tropical cyclogenesis: a spatial analysis of the southwest Pacific region. Int J Climatol 37:1118-1137. https://doi.org/10.1002/joc.5070

Mallakpour I, Villarini G (2016) Investigating the relationship between the frequency of flooding over the central United States and large-scale climate. Adv Water Resour 92:159-171. https://doi. org/10.1016/j.advwatres.2016.04.008

Matthews AJ (2012) A multiscale framework for the origin and variability of the South Pacific Convergence Zone. Q J R Meteorol Soc 138:1165-1178. https://doi.org/10.1002/qj.1870

Matthews AJ, Hoskins BJ, Slingo JM, Blackburn M (1996) Development of convection along the SPCZ within a Madden-Julian oscillation. Q J R Meteorol Soc 122:669-688. https://doi.org/10.1002/ qj.49712253106

McAneney J, van den Honert R, Yeo S (2017) Stationarity of major flood frequencies and heights on the Ba River, Fiji, over a 122year record. Int J Climatol 37:171-178. https://doi.org/10.1002/ joc. 4989

McBride JL, Ebert EE (2000) Verification of quantitative precipitation forecasts from operational numerical weather prediction models over Australia. Weather Forecast 15:103-121. https:// doi.org/10.1175/1520-0434(2000)015<0103:VOQPFF > 2.0.CO;2

McGree S, Yeo SW, Devi S (2010) Flooding in the Fiji Islands between 1840 and 2009. Risk Frontiers Technical Report, Risk Frontiers, Macquarie University, Australia 
McGree S et al (2014) An updated assessment of trends and variability in total and extreme rainfall in the western Pacific. Int J Climatol 34:2775-2791. https://doi.org/10.1002/joc.3874

McGree S et al (2019) Recent changes in mean and extreme temperature and precipitation in the Western Pacific Islands. J Climate 32:4919-4941. https://doi.org/10.1175/JCLI-D-18-0748.1

McPhaden MJ, Zebiak SE, Glantz MH (2006) ENSO as an integrating concept in earth science. Science 314:1740. https://doi. org/10.1126/science. 1132588

Ng B, Walsh K, Lavender S (2015) The contribution of tropical cyclones to rainfall in northwest Australia. Int J Climatol 35:2689-2697. https://doi.org/10.1002/joc.4148

Nurse LA, McLean RF, Agard J, Duvat-Magnan V, Pelesikoti N, Tompkins E, Webb A, Briguglio L (2014) Small Islands. In: Intergovernmental Panel on Climate C (ed) Climate change 2014impacts, adaptation and vulnerability: Part B: Regional Aspects: Working Group II Contribution to the IPCC Fifth Assessment Report: volume 2: regional aspects, vol 2. Cambridge University Press, Cambridge, pp 1613-1654. https://doi.org/10.1017/CBO97 81107415386.009

Paerl HW, Hall NS, Hounshell AG, Luettich RA, Rossignol KL, Osburn CL, Bales J (2019) Recent increase in catastrophic tropical cyclone flooding in coastal North Carolina, USA: Long-term observations suggest a regime shift. Sci Rep 9:10620. https://doi. org/10.1038/s41598-019-46928-9

Peduzzi P, Chatenoux B, Dao H, De Bono A, Herold C, Kossin J, Mouton F, Nordbeck O (2012) Global trends in tropical cyclone risk. Nat Climate Change 2:289-294. https://doi.org/10.1038/ nclimate 1410

Power SB, Callaghan J (2016) Variability in severe coastal flooding, associated storms, and death tolls in Southeastern Australia since the Mid-Nineteenth Century. J Appl Meteorol Climatol 55:11391149. https://doi.org/10.1175/JAMC-D-15-0146.1

Power S, Casey T, Folland C, Colman A, Mehta V (1999) Inter-decadal modulation of the impact of ENSO on Australia. Climate Dyn 15:319-324. https://doi.org/10.1007/s003820050284

Ramsay HA, Camargo SJ, Kim D (2012) Cluster analysis of tropical cyclone tracks in the Southern Hemisphere. Climate Dyn 39:897917. https://doi.org/10.1007/s00382-011-1225-8

Ren F, Wu G, Dong W, Wang X, Wang Y, Ai W, Li W (2006) Changes in tropical cyclone precipitation over China. Geophys Res Lett. https://doi.org/10.1029/2006GL027951

Rodgers EB, Adler RF, Pierce HF (2000) Contribution of tropical cyclones to the north Pacific climatological rainfall as observed from satellites. J Appl Meteorol 39:1658-1678. https ://doi.org/10.1175/1520-0450(2000)039\%3c1658:COTCT $\mathrm{T} \% 3 \mathrm{e} 2.0 . \mathrm{CO} ; 2$

Salinger MJ, Renwick JA, Mullan AB (2001) Interdecadal Pacific oscillation and south Pacific climate. Int J Climatol 21:1705-1721. https://doi.org/10.1002/joc.691

Sharma KK, Verdon-Kidd DC, Magee AD (2019) Decadal variability of tropical cyclogenesis and decay in the southwest Pacific. Int $\mathbf{J}$ Climatol. https://doi.org/10.1002/joc.6368

Shepherd JM, Grundstein A, Mote TL (2007) Quantifying the contribution of tropical cyclones to extreme rainfall along the coastal southeastern United States. Geophys Res Lett 34:L23810. https ://doi.org/10.1029/2007GL031694

Tauvale L, Tsuboki K (2019) Characteristics of tropical cyclones in the Southwest Pacific. J Meteorol Soc Jpn Ser II 97(3):711-731
Trenberth KE (1997) The Definition of El Niño. Bull Am Meteorol Soc 78:2771-2778. https://doi.org/10.1175/15200477(1997)078\%3c2771:TDOENO\%3e2.0.CO;2

Villarini G, Denniston RF (2015) Contribution of tropical cyclones to extreme rainfall in Australia. Int J Climatol 36:1019-1025. https ://doi.org/10.1002/joc.4393

Villarini G, Serinaldi F, Smith JA, Krajewski WF (2009) On the stationarity of annual flood peaks in the continental United States during the 20th century. Water Resour Res 45:W08417. https:// doi.org/10.1029/2008WR007645

Villarini G, Smith JA, Ntelekos AA, Schwarz U (2011) Annual maximum and peaks-over-threshold analyses of daily rainfall accumulations for Austria. J Geophys Res Atmos. https://doi. org/10.1029/2010JD015038

Villarini G, Goska R, Smith JA, Vecchi GA (2014) North Atlantic tropical cyclones and U.S flooding. Bull Am Meteorol Soc 95:13811388. https://doi.org/10.1175/BAMS-D-13-00060.1

Vincent DG (1994) The south Pacific convergence zone (SPCZ): a review. Mon Weather Rev 122:1949-1970. https:// doi.org/10.1175/1520-0493(1994)122\%3c1949:TSPCZ $\mathrm{A} \% 3 \mathrm{e} 2.0 . \mathrm{CO} ; 2$

Vincent EM, Lengaigne M, Menkes CE, Jourdain NC, Marchesiello $P$, Madec G (2011) Interannual variability of the South Pacific Convergence Zone and implications for tropical cyclone genesis. Climate Dyn 36:1881-1896. https://doi.org/10.1007/s0038 2-009-0716-3

Wang Y, Wang Y, Fudeyasu H (2009) The role of Typhoon Songda (2004) in producing distantly located heavy rainfall in Japan. Mon Weather Rev 137:3699-3716. https://doi.org/10.1175/2009M WR2933.1

Wheeler MC, Hendon HH (2004) An all-season real-time multivariate MJO index: development of an index for monitoring and prediction. Mon Weather Rev 132:1917-1932. https ://doi.org/10.1175/1520-0493(2004)132\%3c1917:AARMM $\mathrm{I} \% 3 \mathrm{e} 2.0 . \mathrm{CO} ; 2$

Woodruff JD, Irish JL, Camargo SJ (2013) Coastal flooding by tropical cyclones and sea-level rise. Nature 504:44-52. https://doi. org/10.1038/nature 12855

Yamada Y, Satoh M, Sugi M, Kodama C, Noda AT, Nakano M, Nasuno T (2017) Response of tropical cyclone activity and structure to global warming in a high-resolution global nonhydrostatic model. J Climate 30:9703-9724. https://doi.org/10.1175/ JCLI-D-17-0068.1

Zhang C (2005) Madden-Julian oscillation. Rev Geophys. https://doi. org/10.1029/2004RG000158

Zhang C, Wang Y (2017) Projected future changes of tropical cyclone activity over the western north and south Pacific in a 20-km-mesh regional climate model. J Climate 30:5923-5941

Zhang Q, Gu X, Li J, Shi P, Singh VP (2018) The impact of tropical cyclones on extreme precipitation over coastal and inland areas of China and its association to ENSO. J Climate 31:1865-1880. https://doi.org/10.1175/JCLI-D-17-0474.1

Publisher's Note Springer Nature remains neutral with regard to jurisdictional claims in published maps and institutional affiliations. 